Townend Ian (Orcid ID: 0000-0003-2101-3858)

Zhou Zeng (Orcid ID: 0000-0002-4745-1621)

Guo Leicheng (Orcid ID: 0000-0002-1261-2536)

Coco Giovanni (Orcid ID: 0000-0001-7435-1602)

\title{
A morphological investigation of marine transgression in estuaries
}

$$
\text { Ian Townend }{ }^{1,2} \text {, Zeng Zhou }{ }^{1} \text {, Leicheng Guo }{ }^{3} \text {, Giovanni Coco }{ }^{4}
$$

1 State Key Laboratory of Hydrology-Water Resources and Hydraulic Engineering,

Hohai University, Nanjing, China

${ }^{2}$ School of Ocean and Earth Science, University of Southampton, UK

${ }^{3}$ State Key Lab of Estuarine and Coastal Research, East China Normal University,

Shanghai, China

${ }^{4}$ Faculty of Science, University of Auckland, New Zealand

Corresponding author: Z. Zhou, College of Harbour, Coastal and Offshore

engineering, Hohai University, Xi Kang Road 1, Nanjing Jiangsu 210098, China

Email: zeng.zhou@hhu.edu.cn, Tel: +8613815408337

This article has been accepted for publication and undergone full peer review but has not been through the copyediting, typesetting, pagination and proofreading process which may lead to differences between this version and the Version of Record. Please cite this article as doi: $10.1002 /$ esp. 5050 


\section{Abstract}

The landscape setting for an estuary varies widely and is an important aspect of determining how they evolve. This paper focusses on alluvial estuaries in river valleys and how they respond to sea level rise. We examine the implications of marine transgression, as a response to sea level rise, where the estuary moves upwards and landwards to maintain its position in the tidal frame (so-called "stratigraphic rollover"). Here we encapsulate such kinematic movement of the estuary morphology using a 'morphokinematic' model, to assess the potential response to sea level rise and sediment supply. The model of the estuary form includes a single convergent channel, intertidal and surrounding flood plains (the valley) and allows the relative importance of the space available for deposition of sediments, the accommodation space, to be investigated as a function of rates of sea level rise and sediment supply. The transgression of the system is determined using a sediment mass balance, taking account of any supply from the river and marine environment. Model results confirm that the transgression distance, measured as the distance the entity moves landward, varies in proportion to the change in accommodation space, which mainly depends on the flood plain area. As the size of the flood plain reduces, the transgression distance is less and the system becomes much more sensitive to changes in the rate of sea level rise, or changes in sediment supply. The greater demand for sediment when a flood plain is present results in greater cannibalisation of the estuary form (i.e. greater landward movement) to meet the sediment demand. When the flood plain is disconnected from the estuary, the synergistic relationship is lost and the accommodation space increases. The capacity for restoration will depend on the availability of sediment and the prevailing rate of sea level rise. 


\section{Key Words}

Estuary, sea level rise, morphology, accommodation space, sediment budget, constraints, morphokinematic model

\section{Introduction}

The landscape setting for an estuary varies widely and the primary origin is an important component of any estuary classification (Hume and Herdendorf, 1988). The origin is determined by the antecedent landform of which there are three broad classes, namely: surface deformations of the hard geology (tectonic, volcanic and glacial), marine derived embayments, and fluvial/glacial river valleys (Townend, 2012). The focus in this paper is on estuaries in river valleys and how they may adjust their position in response to sea level rise, or, in other words, the marine transgression of this class of estuary system, very much in line with the definition of an estuary proposed by Dalrymple (2006):

"an estuary is a transgressive coastal environment at the mouth of a river, that receives sediment from both fluvial and marine sources, and that contains facies influenced by tide, wave and fluvial processes".

There is good evidence that confirms the occurrence of marine transgression of estuaries in river valleys, under the influence of sea level rise, where marine and fluvial sediments are being imported (Dalrymple, 2006; Rees et al., 2000; Woodroffe et al., 1989). This occurs over geological time scales, and here we investigate the implications of estuary transgression over much shorter time scales, i.e., decades and centuries. We consider the form of the estuarine water body within an, often more extensive, incised river valley form. The volumetric difference between the two forms defines the accommodation space and, when infilled with sediment, forms the flood plain alongside the estuary (see Figure 1). This geomorphological conceptual model focusses on how accommodation space changes in time. Figure 1 illustrates how, as 
sea level rises and the coast retreats, tides are able to propagate further landward, along the river channel. With a further rise in sea level, the tide propagates further up the valley and, depending on the width of the valley, may also begin to deposit sediment on the bed and valley sides. Reconstructions of the Holocene basal surface suggests that some erosion of the river valley may also take place in this early phase, depending on the hydrodynamic and sedimentological conditions (Rees et al., 2000). The available accommodation space can also determine the extent of flood plain, marshland and channel meandering within the river valley (Townend et al., 2007). The amount of accommodation space available, at any point in time, depends on the interplay of the valley topography, the size of the estuary and rate of sea level rise (which has varied significantly over the Holocene).

Estuaries have variously been considered as a filter of sediments (DiLorenzo, 1988; Kennedy, 1984), or in terms of their capacity to store sediments (Allen, 1990; Avoine, 1987; O'Connor, 1987). However, perhaps the most extensive insights have been drawn from the efforts to interpret sedimentary records, in order to better understand the origin and evolution of estuary systems (e.g. Heap et al., 2004; Heap and Nichol, 1997; Roy, 1984). The literature on the stratigraphic organisation of estuarine landforms is very extensive but has been given a strong focus by the work of the Society for Sedimentary Geology (SEPM) in a series of Special Publications (Dalrymple et al., 1994; Dalrymple et al., 2006; Posamentier and Walker, 2006), which focus explicitly on incised river valleys, and their evolution in space and time. These have considered many aspects of their evolution, including the location and shape of incised river valleys (Ardies et al., 2002; Zaitlin et al., 1994), how they are filled, the implications of over-filling and the dependency on marine and fluvial sediment supply 
(Dalrymple et al., 2006). As already noted, sea level rise can create excess accommodation space. Provided that a sediment supply exists, estuaries in such settings have a tendency for sedimentary infilling (e.g. see Figure 2 in Rees, 2006; and Figures 8-11 in Rees et al., 2000). It has been suggested that this infilling continues, sediment supply permitting, until the estuary form achieves a dynamic equilibrium in relation to the incident hydrodynamic forces (Pethick, 1994; Pye and Blott, 2014). Observations in the Severn Estuary, have led to the suggestion that once an estuary system reaches this dynamic equilibrium, then infilling serves to maintain the equilibrium whilst adjusting its position to maintain the form relative to the tidal frame (Allen, 1990). The role of limiting factors, such as sediment supply, is not wholly understood, but it has been shown that, under conditions of rising sea level, estuaries have the potential to maintain their form relative to the tidal frame (Townend and Pethick, 2002). To do this the estuary form must move landwards and/or upwards, a process which has been referred to as "estuary rollover", or 'stratigraphic rollover' (Allen, 1990; Pye and Blott, 2014). If the plan form is to be maintained, such a landward migration implies that, in a Eulerian frame of reference, there will be an increase in width, which can be seen as an accompanying lateral migration that is approximately normal to the channel axis. Previous work has described such processes qualitatively drawing on sedimentary and archaeological records. The focus of this paper is to draw out the implications of this process in more quantitative terms, to estimate transgression distances for a range of valley settings. As well as the extensive work on geological records, there has been a similar effort towards understanding the contemporary processes that lead to morphological changes within an estuary. Much focus has been on the role of tidal asymmetry (Dronkers, 1986; Zhou et al., 2018), sediment import (Winterwerp, 2006) and deposition of fine sediments on the tidal flats 
(e.g. van Maren and Winterwerp, 2013). This can be coupled with baroclinic flows driven by density currents that modulate the asymmetry and resultant morphology (e.g. Olabarrieta et al., 2018; Zhou et al., 2020).

More recently, there has been a significant effort on understanding the potential impact of sea level rise. Modelling work has suggested that tidal ranges will change (positively and negatively) across the world's ocean basins (Pickering et al., 2017) and this is supported by observations around the European continental shelf (Idier et al., 2017). Changes to the tides in the adjacent seas, coupled with rising sea levels have the potential to affect other signals, such as the nodal tide, and tidal propagation within the estuary (Du et al., 2018). Such changes alter the tidal prism within the estuary and, whilst the system may seek to restore a morphological equilibrium by importing or exporting sediment, the lag in such a response provides a morphological signal that has been identified in larger systems (Wang and Townend, 2012).

Work at a larger scale suggests that estuary systems have some capacity to keep pace (by which we mean, maintain a volume consistent with an equilibrium state and closely related to the tidal prism) with sea level rise but would ultimately be "drowned" if the rate of sea level change becomes too large, or the sediment supply is not maintained (Rossington et al., 2007; van Goor et al., 2003). A model based on empirical equilibrium hypsometry has been used to investigate the likely impacts of sea level rise for estuaries of varying size around the world (Leuven et al., 2019), suggesting that larger systems are more sensitive to sediment availability, whereas smaller systems may be susceptible to tidal amplification and greater flood risk. Estuary widening, by increasing the plan area at high water, was shown to potentially mitigate such impacts. 
A key assumption in many of the morphological models that have sought to investigate the impact of sea level rise is the assumption that the estuary will seek an equilibrium morphology (Leuven et al., 2019; van Goor et al., 2003). Given that the forcing conditions are continually changing over a range of time-scales, it is difficult to demonstrate that equilibrium exists in other than a dynamic sense of defining a goal which the system is continuously chasing (Zhou et al., 2017). Considering the system response over Holocene timescales provides one means of demonstrating that this is a plausible assumption (Leuven et al., 2019; Townend et al., 2007). For example, the stratigraphic work of Rees et al. (2000) and observed changes in morphology of an estuary over a much shorter time-scale (150 years) were shown to be consistent (Townend et al., 2007). That estuary systems are also capable of tracking relatively short-term signals such as the lunar nodal tide (Wang and Townend, 2012), further supports the idea that at least some systems are tracking an equilibrium. This would be a Type II dynamic equilibrium in the classification of equilibrium proposed by Zhou et al (2017), or a directional dynamic equilibrium, as proposed by Pye and Blott (2014). Directional dynamic equilibrium describes the situation where "the geometric proportions of the estuary channels and flats remain essentially constant but the estuary overall rises in elevation or moves landwards" (Pye and Blott, 2014).

However, most estuarine modelling of the response to sea level rise has been confined to changes within a water body defined by the high-water line and, in a few cases, its immediate margins (e.g. Leuven et al., 2019). This ignores the important role of accommodation space available on the surrounding flood plain under conditions of sea level rise and the potential for the system to expand, contract and/or move landwards. Here we explicitly define an estuary as a morphological 'form' moving within an antecedent river valley. This defines the space available for a flood plain, in 
order to examine how the accommodation space influences the potential transgression needed to ensure that the system can adjust without needing to import/export additional sediment relative to present day conditions. The availability of accommodation space on the flood plain creates a potential store of sediment, which may be infilled by various mechanisms, such as episodic flood events occupying the flood plain and depositing sediment, channel migration, or changes in tidal propagation that lead to more regular inundation along the channel margins (and may or may not increase the tidal prism).

\section{Method}

To clarify how the adopted approach differs from more common process-based morphodynamic modelling methods and the reasons for choosing this approach, we begin by outlining our modelling rationale. We then provide a concise summary of the model with further details provided in the Supplementary Information (SI).

\section{Model Rationale}

The morphology of the incised river valley provides an antecedent control on contemporary estuary formation and evolution. The key properties of the valley that determine these controls are:

(i) the river discharge, which is strongly correlated to the size of the drainage basin;

(ii) the valley slope, which depends on the size and relief of the valley;

(iii) the depth of the Holocene basal surface, at or near the coast. This may be eroded as channels form and infilled as sea levels rise, and/or the coastline retreats.

Within this setting, the estuary is controlled by the forcing due to sea level, tides, and river discharge (wind-waves are considered a second-order influence in the current 
context). The other key control, in a depositional environment, is the sediment supply from both marine and fluvial sources. These exogenous parameters have been shown to be sufficient to capture the general form of estuaries in terms of plan area, volume and cross-sectional form, whilst neglecting the detail introduced by banks, shoals and bifurcating channels (Townend, 2010; Townend, 2012). This approach relies on three key assumptions, namely that:

(i) the estuary form can be represented by a shape determined using minimum work arguments for the component parts, e.g. convergent plan form, channel and intertidal cross-sections (Townend, 2012);

(ii) the length of the system is determined by the intersection of the tidal surface with the valley slope, so is known a priori. This is distinct from low-lying alluvial systems for which the length is determined by the morphodynamics of the system (Seminara et al., 2010);

(iii) the discharge and valley slope at the tidal limit define a river channel and the estuary must converge to this section. The need to introduce a means of estimating the width of the system arises because the defining equations do not allow the width or cross-sectional area to be determined based on the governing equations alone (Davies and Woodroffe, 2010) and several researchers have resolved the issue using the river dimensions as an additional control (Leuven et al., 2018; Savenije, 2015; Townend, 2012).

These two components, valley and estuary, are linked by sediment deposition. River valleys may constrain the estuary system, so limiting the dimensions of the estuary, or they can be substantially larger. For example, the Humber river valley is 2-3 times the width of the present day estuary (Rees et al., 2000). Furthermore, oversized river valleys provide accommodation space that has progressively infilled over the 
Holocene in a range of different environments (Dalrymple et al., 2006; Posamentier and Walker, 2006; Shi and Lamb, 1991). Whilst in some cases, such as prograding deltas, this is heavily dependent upon the fluvial sediment load, for the type of estuary considered here, the dominant source is marine, which can supply $80-90 \%$ of the sediment facies deposited over the Holocene (Rees, 2006; Shi and Lamb, 1991).

Our focus is on the implications of sea level rise. As already noted, other external conditions, such as tidal range or sediment supply, may also influence the response and some sensitivity tests were undertaken to check the relative importance of these variables. Hence by assuming the external conditions - namely tidal range, river discharge and sediment supply (marine and fluvial) - are constant, the properties that define the form do not change under sea level rise (Townend, 2010, 2012). Hence the predetermined rates of convergence can be used and this simplifies the computation required with no loss of completeness, given the underlying assumptions of the model. Of particular interest in this paper, is how the setting can influence the response of the estuary to sea level rise. We focus on the system as an entity, rather than the internal detail of the constituent morphological features. The problem is therefore posed as an object, in this case the estuary form, that can remain unchanged, move upwards, or move upwards and landwards. To be able to quantify this, we need to be able to define a representative form for the essential dimensions of the estuary and the river valley. For this analysis, the detailed form of the internal processes are not needed. This is akin to the aggregation that is used in models such as ASMITA (Stive and Wang, 2003; Wang et al., 2020), which considers the delta, channel and tidal flats as the geomorphological resolution of relevance.

The approach is similar to the model of Leuven et al (2019) who use an empirically derived description of estuary form, coupled with a 1-D hydraulic model to estimate 
the response to sea level, tidal and river discharge changes. In this model the estuary form is determined from theoretical arguments, which have been tested against observations, coupled with a quasi-analytical model of tidal propagation taking account of river discharge. The key addition here is to consider the extent to which the morphological entity is stationary, as assumed by Leuven et al (2019), or migrates landwards as a function of erosion on the open coast, the relief of the valley and the availability of accommodation space.

It might be argued that the problem could be addressed with the current generation of morphodynamic models. Our view is that this adds complexity and provides spurious additional detail which is quite computationally time-consuming while does not necessarily provide more insight. To our knowledge, the morphological interaction between an estuary and surrounding flood plain has not been modelled. In part, this is because important process descriptions in this class of models are the subject of current research, including bank erosion (Zhao et al., 2019), the influence of vegetation and flood-plain deposition and erosion (Brückner et al., 2019). In addition, as additional degrees of freedom are added to this type of model, the agreement in the morphology predicted by different models, supposedly solving the same physical descriptions, clearly diverge (see, for example, Figure 8 in Coco et al., 2013). Circumventing these limitations allows some initial insights into the potential implications of marine transgression of estuaries.

\section{Summary of model}

To translate the conceptual model of estuary transgression, derived from a synthesis of sedimentological investigations, to a more quantitative formulation requires the following components:

(i) an estuary morphology (essentially a non-linear prismatic 3-D form); 
(ii) a valley morphology (again a non-linear prismatic 3-D form that is larger than the estuary form);

(iii) a description of tidal propagation to define the tidal limit and the spring tide high water surface along the estuary (the flood plain is assumed to be marginally above this level and it should be noted that this is not a horizontal surface along the valley - see Figure 5 in SI);

(iv) an estimate of any sediment exchange with the surroundings (river input and marine input or output);

(v) a definition of any constraints on the system, such as non-erodible geology, seawalls, etc.

In our approach, an estuary is considered as an 'object' that moves within a valley in response to sea level rise. By assuming that an equilibrium form maintains its shape relative to the tidal frame, the transgression distance depends on the accommodation space of the surrounding flood plain. If the flood plains are to maintain their elevation relative to high water as sea levels rise, a supply of sediment is required. As already noted, this can be estimated without considering the import or export of sediment (Townend and Pethick, 2002), nor the related transport mechanisms. However, to understand the extent to which the transgression distance might be influenced by ongoing sediment exchange this is also included in the sediment mass balance. It is worth emphasising that this model considers how the large-scale morphology of an estuarine river valley changes with time. It is not a process-based model and does not consider tidal hydraulics, wave and density-driven processes that move sediment and alter the bed level. It might more appropriately be called a morphokinematic model, as distinct from a morphodynamic model. 
A 3-D description of an idealised estuary morphology (component (i) in above summary) can be developed by specifying the geometry variation in any two dimensions, e.g. along channel and plan form ( $x$ and $y$ ) or plan form and cross-channel ( $y$ and $z$ ), etc. The dimensions of the system (width, length, rate of convergence, etc.) can be specified, or derived based on the physical setting, sedimentology and hydrodynamics (Townend, 2010; 2012). The resultant idealised form captures the dominant longitudinal and cross-sectional variations, whilst ignoring meanders. This was the approach used for the estuary component, which was then embedded in a valley morphology, component (ii), developed using a similar approach. The water surface, component (iii), is required to define the flood plain elevation along the estuary and the level at which the estuary intersects the surrounding valley form (i.e. the elevation of the flood plain and the tidal limit). The high water surface was obtained using a hydrodynamic model for convergent estuaries that takes account of both tidal forcing and river flow (Cai et al., 2014). For long channels the surface is not horizontal and results in a discernible variation in the along-channel level of the flood plain (see Figure SI 6).

The resultant representation was then used to explore the implications of translating the 3D estuary form. A mass balance was sought that requires no additional import or export of sediment, based on raising the form to maintain its position in the tidal frame and moving the form landward. The potential for the transgression distance to be modified by import or export of sediment from the river and the marine environment, component (iv), was incorporated using a simple single-element sediment balance model - ASMITA (Stive and Wang, 2003; Townend et al., 2016a). Further details of the model formulation and the iterative procedure used are provided in the Supplementary Information. 


\section{Estimation of Transgression Distance}

With a surrounding flood plain at, or just above, high water level, raising the system (estuary channel and water level) implies that the system rises above the surrounding land. When this happens, the likelihood of flooding on extreme events increases and sediment-laden water would be transported onto the flood plains giving rise to accretion and the progressive increase in the elevation of the flood plains. The concept of estuary transgression suggests that for a given sea level rise, the system can adjust by moving landward and in doing so may or may not need to import or export sediment, depending on the sediment supply and the demands of the accommodation space. Conceptually, this implies that there is a landward transgression distance that requires zero sediment exchange (i.e. no sediment import or export), where the estuary form moves upwards and landwards to maintain its initial form relative to mean tide level, (Figure 2). This is a mass conservation transformation of the system, analogous to the cross-shore mass balance proposed for beach profiles by Bruun (1962). Ignoring the potential for sediment import/export, the distance that the form needs to move for there to be no net volume change determines the transgression distance ( $T_{E}$ in Figure 2). There is an extension of the system at the seaward end (by an amount $T_{E}$ ) but this may be reduced by any erosion on the open coast, $T_{C}$, which may also be transgressing in response to sea level rise. The length of the estuary may also change due to any lengthening or shortening at the landward end, $T_{R}$, that depends on the valley slope, and any change in tidal propagation. For this analysis, transgression of the open coast has been ignored. In a fixed frame of reference, the landward transgression of the initial form results in a widening, or lateral expansion of the system, as indicated by changes in the high water line, depicted as solid and dashed green lines in Figure 2, for the pre- and post-transgression cases, respectively. 


\section{Role of constraints}

Allen (1990) was able to infer the change in the Severn Estuary from stratigraphic evidence: "It would therefore seem that the environments of the inner Bristol ChannelSevern Estuary, and the sediments associated with them, are together retreating inland by a process of stratigraphical "roll-over" ". One of Allen's (1990) lines of evidence for his conceptual model of estuary transgression, Figure 3 (a) was the influence of geologically harder rock strata that outcrop locally along the estuary (Palaeozoic strata and trimmed bed rock spurs and islands in Figure 1 of Allen, 1990). Extracting the widths of the estuary at high and low water, the location of these spurs or sills are readily identified (denoted by the arrows) and demonstrate the strong influence of geological constraints on the morphology of this estuary (Figure 3(b)). Constraints are introduced into the model, component $(v)$, by defining reaches of the model over which either the bed coordinates are fixed, or the high-water margin is fixed.

\section{Model setup}

The model was used as a 'toy model' (Haldane and May, 2011; Murray, 2007) to illustrate potential system behaviour under a range of different conditions and constraints, rather than to predict changes for a real system. Many of the river valleys in the UK are known to have infilled with marine sediments over the Holocene and are therefore likely to have been subject to marine transgression. We considered 3 idealised systems that were representative of the range of systems typically found.

The three cases were designed to capture valleys that ranged from those that rose rapidly inland from the coast, to those that remained relatively flat. These represented along valley aspect ratios that varied from 100 to 3000 . The key dimensions of the valleys and properties of the estuaries are given in Table 1, with further details 
provided in the SI. Illustrations of the resultant form and its component parts, for all three valleys, are shown in Figure 4.

The model can be run in two modes. One mode uses a single iteration, considering only transgression with no sediment flux or hydrodynamic adjustments and this is referred to as the simple kinematic model (SK model). The second mode is a quasidynamic kinematic model (QDK model) and runs iteratively, updating the water surface, sediment exchange and estuary-valley form at each time step. The volume balance is obtained by integrating over the tidal reach of the model domain. For the long valleys the tidal limit is defined as where the tidal range becomes small (threshold of $0.05 \mathrm{~m}$ ), whereas for short, steep valleys it is where the high-water level intersects the longitudinal valley slope.

The model domain was set to be wider than the width of the valley at the mouth and longer than the length of the estuary to allow for transgression of the tidal limit. For the short valley, the grid size was $50 \mathrm{~m} \times 10 \mathrm{~m}$ whereas for the longer valleys a resolution of $200 \mathrm{~m} \times 40 \mathrm{~m}$ was used. With such a fine grid, the model is not particularly sensitive to small variations in grid resolution (e.g. $x 2$ or $x 0.5$ ). However, the results can be sensitive to the time step used. Based on a series of sensitivity tests a time step of 10 years was found to be sufficient (see SI for details).

Two sea level rise cases were considered, one using a linear rate of $2 \mathrm{~mm} / \mathrm{year}$ and one using a rate that increases exponentially from $1 \mathrm{~mm} /$ year in 1900 , to $3 \mathrm{~mm} /$ year by 2000 and $9 \mathrm{~mm} /$ year by 2100 . The simulation was undertaken for a period of 100 years (from the year 2000 when using the accelerating rate of rise).

To consider the influence of the flood plain, four cases were considered, using:

- the valley as defined in Table 1;

- $\quad$ half the valley width as defined in Table 1;

This article is protected by copyright. All rights reserved. 
- valley width equal to estuary mouth width; and

an estuary constrained at high water.

These different valley forms are illustrated in Figure 5. Each configuration was tested for the two sea level rise cases. In addition, the sensitivity to changes in tidal amplitude and sediment concentration was also examined. For the former a variation of $+/-10 \%$ of the tidal amplitude was tested. This is consistent with the variations predicted for the European Continental Shelf and a $2 \mathrm{~m}$ change in sea levels by Pickering et al. (2012). Sediment supply can be adjusted in the model by changing the equilibrium concentration and this was varied up and down by a factor of 2 ; a range that is consistent with the annual variability in some UK estuaries (e.g. Uncles et al., 1999). The combinations considered are summarised in Table 2.

The influence of constraints was examined by fixing the bed of the model at two locations, between 1-3 km and 30-33 km from the mouth, such that the bed could accrete but it could not erode over these lengths. To highlight the influence of these constraints, the scenario included the flood plain and was run for a $0.5 \mathrm{~m}$ increase in sea level.

\section{Results}

To enable a direct comparison of the different cases, transgression distances are presented as distances per $\mathrm{mm}$ of sea level rise and the plan areas of the flood plain have been normalised relative to the estuary plan area at high water. The results for the two sea level rise cases and the various river-valley configurations are shown in Figure 6 and the results are tabulated in the SI. For the long valley cases the SK model (open symbols) predicts up to double the transgression estimated using the QDK model (filled symbols), whereas the results are comparable for the short valley. Furthermore, the SK model predicts different amounts of transgression for different 
rates of SLR, despite the normalisation (compare open circles and triangles). In contrast, the QDK model results for different rates of SLR are similar, reflecting the importance of the sediment supply in moderating the system response. As the area of flood plain increases there is a linear increase in transgression, in proportion to the total plan area (dotted lines). The slope of these lines can be described by a regression relationship with the estuary plan area at high water, $S_{H W}$, as follows:

$$
\frac{d T}{d \hat{S}}=1.55+\left(\frac{S_{H W}}{2.7 e 8}\right), \quad R^{2}=0.93
$$

where $T$ is the transgression distance, and $\hat{S}$ is the normalised total plan area. With only 3 data points this is a highly tentative regression but provides a preliminary means of scaling the transgression to reflect the extent of the flood plain.

\section{Characteristics of change}

A simple difference plot between the initial bathymetry and the bathymetry after a 0.2 $\mathrm{m}$ rise in sea level is shown in Figure 7(a) for the long, steep half-width valley. Over the flood plain the change is approximately equal to the rise in sea level. Small variations reflect any change in tidal propagation and hence the along-channel variation of high water (see Figure SI 6). Within the channel, the more horizontal surfaces accrete and the more vertical surfaces erode, reflecting the combined effect of warping up and widening as the form moves landwards. The cross-sections in Figure 7, illustrate how the transgression alters sections at locations that are fixed in space (Eulerian view). For the case that includes the flood plain, Figure $7(b)$, there is a warping up of the flood plain, a lateral expansion of the channel and some deepening of the thalweg. When the flood plain is excluded, obviously it no longer keeps pace with sea level rise, Figure 7(c), the lateral expansion is much less and although there 
is some deepening at the mouth, this switches to shallowing (but by an amount less than sea level rise) by a distance of $0.1 \mathrm{~L}$ from the mouth. How this translates into change along the length of the channel will be later illustrated (Figure 12).

The changes over time in properties such as mouth width and depth and estuary length increase in accord with the rate of sea level rise. This is illustrated in Figure 8 for the case including the flood plain and using an accelerated rate of sea level rise, as changes relative to the initial value. It is notable that the relative increase in estuary length is much less than the changes in width and depth at the mouth. This is because the exponential form dictates an exponential increase in the latter as the system translates landwards. However, whilst the estuary length extends by the translation distance, the landward extent is then influenced by the valley slope at the tidal limit and the tidal propagation to the tidal limit. As the case considered is a river valley with a discernible valley slope the extension in length is relatively less.

\section{Sensitivity tests}

The sensitivity of the response to sediment supply and tidal amplitude was tested using the QDK model. The equilibrium sediment concentration determines the amount of sediment imported and this value was halved and doubled, Figure 9. In all cases, the short valley was insensitive to these changes. In contrast the long valleys became more sensitive as the area of the flood plain was reduced. This is because the external supply has a greater influence on the transgression as the flood plain area reduces. This is particularly evident when there is no flood plain. For this case, doubling the equilibrium concentration generates a supply that can itself fill the accommodation space created by sea level rise, without the need for any transgression.

Linearly increasing the tidal amplitude by $+/-10 \%$ resulted in relatively small changes in transgression distance of generally less than $2 \%$, but up to $5 \%$ when there was no 
flood plain. However, changing tidal amplitude does alter the morphology relative to the base case whereas changing the sediment concentration does not. Increasing tidal amplitude, increases the high-water volume (see Figure SI7) and reduces the lower water volume, resulting in a larger tidal prism. For the short steep valley, increasing tidal amplitude reduces the transgression distance, whereas the transgression distances are increased for the long flat valley case. Reducing the tidal amplitude has the opposite effect. For the long steep valley, the change in transgression distance relative to the base case depends on the extent of the flood plain. Hence the response to changes in tidal amplitude also depends on the landscape setting. A direct comparison with Leuven et al. (2019) is difficult because of the different assumptions in the two studies. Nevertheless, we notice that they reported a more significant response in terms of sediment demand and damping/amplification of the tidal wave. This is partly because they considered absolute changes in tidal range that were larger than implied by the results of Pickering et al. (2017) for a $2 \mathrm{~m}$ rise in sea level, and may also be a consequence of assuming a fixed frame of reference, rather than allowing transgression. This is definitely a topic that merits further investigation.

Changing the cross-sectional form in the model from parabolic to rectangular was also tested for the long-steep valley case and found to only alter transgression distances by a few percent. Although not tested, previous results suggest that changing the plan form alters the spatial pattern of erosion and deposition but does not substantially alter the transgression distance (Townend and Pethick, 2002).

\section{Effect of constraints}

The influence of geological constraints, of the sort noted by Allen (1990), Figure 3, was examined in the model by fixing the bed of the model at two locations, over a distance of $2 \mathrm{~km}$, such that the bed could accrete but it could not erode over these 
lengths. This is equivalent to two sills across the estuary. The resultant posttransgression widths of the system at high water, mean tide level and low water are shown in Figure 10. The stepped nature of the form is clear, although the detail close to the hard points is different to that seen in Figure 3 because there is no process in the model to redistribute sediment locally. Nonetheless, the result supports Allen's hypothesis that the "necking", or staggered funnel shape, is indeed evidence of marine transgression, .

\section{Discussion}

As is to be expected, the transgression distance increases with increasing rates of sea level rise. Historic rates of SLR are comparable to the linear rate of $2 \mathrm{~mm} / \mathrm{year}$ that was modelled, whereas the rates projected for the coming century are more comparable with the accelerated SLR case modelled. The results suggest that the transgression distances could more than double as the rate of SLR increases. This may mean that changes due to transgression can be detected in more estuaries, as the signal becomes stronger. The transgression distance is also sensitive to sediment supply but far less sensitive to changes in tidal amplitude. For the former, increasing sediment supply reduces the transgression to the point where there is none, or, if there is an excess supply, the system starts to prograde, as is the case for river deltas. If supply is reduced the estimates are closer to the transgression estimated without considering sediment supply (as estimated by the SK version of the model).

Deposition over the flood plain is assumed to be a sediment demand to allow the surface, defined by the evolving high-water surface, to keep pace. It is therefore a sediment mass balance, similar to the approach adopted by Bamunawala et al (2020). One implication of this assumption is that the idealised plan shape of the valley 
adopted for this study has no effect because the sediment demand is constant for a given plan area. However, in real valleys the plan form does not vary monotonically along the valley, hence the accommodation space is spatially more heterogeneous and this is more likely to influence the system response.

\section{Observational evidence}

The QDK version of the model includes an aggregated sediment model, which seeks to balance sediment concentration between the estuary and the external environment. A consequence is that, as sea level rises, the accommodation space in the estuary increases, which is equivalent to increasing the concentration gradient, hence the import of sediment varies with the rate of sea level rise (van Goor et al., 2003). In some estuaries a study of the borehole records and geo-chemistry of the sediments deposited has enabled a (relatively) detailed reconstruction of sedimentation in the estuary. For example, in the Humber estuary, on the East coast of the UK, a detailed Holocene reconstruction (Rees et al., 2006; Rees et al., 2000) suggests that the rate of marine infilling has, on average, been around $2.2 \times 10^{5} \mathrm{~m}^{3} /$ year over the last 2000 years, when sea levels rose at between 1 and $2 \mathrm{~mm} /$ year (Townend et al., 2007). This means that over the Holocene there has been enough sediment for the valley basin to progressively infill. This led Rees (2006) to suggest that topographic controls influenced the character of the sediments deposited and sea level rise drove the landward migration of sediment facies such as the tidal delta. Over historic timescales (decades-centuries) previous work has shown that the rate of infilling is consistent with sea level rise and other longer-term tidal forcing conditions (Townend et al., 2007) and that the system is tracking the lunar nodal tidal cycle ( 18.6 years) with a time lag that

is consistent with theoretical arguments (Wang and Townend, 2012). The latter suggests that the rate of sediment import does vary with the forcing conditions and the time to transport sediment into the system determines the lag in the volumetric 
response. This may seem odd given the relatively low sediment concentration along the adjacent coast but reflects the fact that there is a large volume of sediment in transport on every tide (Townend and Whitehead, 2003) and tidal pumping (Scully and Friedrichs, 2007) provides a mechanism for increasing the sediment concentrations within the estuary relative to the background marine levels (Townend et al., 2016b). Nonetheless it is clear that the response is highly sensitive to the availability of sediment and any changes in the supply (marine and fluvial) could alter the balance and hence the likely transgression distance.

The rate of landward transgression with a $2 \mathrm{~mm} /$ year rate of SLR is around $1.5 \mathrm{~m} /$ year when the flood plain is excluded and increases to by an order of magnitude for the full valley case modelled. This rate increases to around $4 \mathrm{~m} /$ year for the accelerating SLR case. The mouth position was assumed fixed, and hence implies no shoreline erosion on the open coast. This may be reasonable over a 100-year timescale but over geological timescale it is not. In the case of the Humber there has been erosion of the shoreface ramp for millennia (Wingfield and Evans, 1998) and this continues with the low water mark retreating at a rate of 1-2 m/year (Townend and McLaren, 1988). However, there are extensive defences, especially to the south and this is constraining the transgression of high water. Taking the low water erosion rate as a guide, this is consistent with the transgression rate of the estuary when the flood plain is excluded, suggesting that the estuary and shoreface could retreat in unison. In contrast, when a large flood plain is included, the estuary transgression rate is substantially faster (perhaps by an order of magnitude) suggesting that such an estuary would lengthen and hence substantially change dimensions, in terms of length, and width and depth at the mouth (although the overall length will also depend on the slope of the river valley at the tidal limit). These projections are, of course, predicated on the 
assumptions that tide and river conditions remain constant and that the sediment supply can meet the demand.

\section{Estimating estuary transgression}

The model results provide a range of estimates for valleys of different shapes and sizes, with different rates of sea level rise and sediment supply. These data were used to establish an empirical method for estimating the rate, or amount, of transgression. The so called 'Bruun rule' uses a simple scaling of the length and depth of a crossshore profile to estimate the retreat for a given rise in sea level (Bruun, 1962). Applying this concept to an estuary with no flood plain, and noting that the form is 3-dimensional, we found that the ratio of the cross-sectional area-convergence length, $L_{a}$, to the hydraulic depth at high water, $h_{H W}$ provides a good estimate of the SK transgression distances (i.e. the distances obtained ignoring sediment exchange with the outside environment). An alternative using the ratio of the width-convergence length and the change in the depth of the thalweg along the length of the estuary also gives reasonable estimates. This value needs to be corrected to account for any sediment exchange. For this we examined how the transgression distance, $T_{e 0}$, varied as a function of sediment supply, $V_{\text {ext }}$ and again found that this could be estimated using $L_{a}$ and $h_{H W}$. Finally, we used the variation of the transgression distance as a function of the normalised plan area, Eq. 1, to estimate how the size of the flood plain alters the transgression distance.

An estimate of the volume imported or exported can be made by simplifying the single element ASMITA model (van Goor et al., 2003) by assuming that the ratio of initial volume to tidal prism defines the equilibrium condition and that the tidal velocity at the mouth, $u$, is approximately unity. The rate of change of morphological volume (which is equivalent to sediment exchange) has the form: 


$$
\frac{\mathrm{d} V}{\mathrm{~d} t}=\frac{1}{c_{\mathrm{b}}} \cdot \frac{w \delta c_{\mathrm{E}} S}{\delta+w S}[\gamma-1] \quad \text { where } \quad \gamma \simeq\left(\frac{V}{V+S \cdot \Delta s l r}\right)^{n} \text { and } \delta=\frac{4 V A}{w S T_{p}}
$$

where $V$ is the volume, $S$ the plan area and $A$ the cross-sectional area at the mouth. In addition, $c_{b}$ is the concentration of the bed, $w$ is the vertical exchange, which is approximated as the sediment fall velocity, $C_{E}$ is the global equilibrium concentration, $\Delta s / r$ is the rate of change of sea level and $\delta$ is the horizontal exchange, estimated using the tidal excursion, where $T_{p}$ is the tidal period.

The above can be summarised, in conjunction with Eq. 1 and 2 as:

$$
\begin{aligned}
& T_{e 0}=\frac{L_{a}}{h_{H W}} \cdot 10^{-3} \mathrm{~m} / \mathrm{mm} \text { of slr } \\
& \frac{d T_{e 0}}{d V_{e x t}}=\frac{k}{L_{a} h_{H W}} \mathrm{~m} / \mathrm{m}^{3} \text {, where } k \text { is a constant }(\approx 2) \\
& T_{e 0}^{*}=T_{e 0}-V_{e x t} \frac{d T_{e 0}}{d V_{e x t}} \quad \text { where } V_{e x t} \text { is obtained using Eq.2 } \\
& \text { and } \quad T_{e}=T_{e 0}^{*}+(\hat{S}-1) \frac{d T}{d \hat{S}}
\end{aligned}
$$

where $T_{e 0}$ is the SK transgression for an estuary with no flood plain, $T_{e 0}^{*}$ takes account of sediment supply for the same case and $T_{e}$ takes account of the extent of the flood plain. This empirical model provides a reasonable estimate of the transgression distance per mm of SLR for the range of cases examined, Figure 11. Whilst this may be sufficient to estimate the order of magnitude of transgression, further testing, for a wider range of forms and conditions, is required before this can be considered as anything more than a tentative estimator 
Implications of estuary transgression The different potential modes of response are summarised in Figure 12. When the coast and estuary retreat in unison, it is possible to conceive of the system maintaining its form as it transgresses landwards, Figure 12(a). This was the case considered by Townend and Pethick (2002). For this case, the slope to seawards of the mouth is determined by:

transgression slope $=$ transgression distance/sea level rise, over the time interval considered because the mouth depth stays constant. However if the coast does not erode as fast, or the rate of estuary transgression is large because of a large flood plain demand for sediment, then the estuary extends in length at the seaward end and, if not constrained, increases in width and depth at the mouth, Figure 12(b). However, in this case the additional deepening at the mouth modifies the transgression slope:

transgression slope $=$ transgression distance/(sea level rise - additional deepening)

As the transgression of the mouth goes to zero so the bed immediately upstream of the mouth is likely to become horizontal. This is also seen in the third case, where the estuary width is also constrained, Figure 12(c). Although seemingly similar, cases (b) and (c) differ in that case (b) maintains the initial form moved landwards and lengthens based on the convergence lengths of the system, whereas case (c) keeps the initial plan form in its initial position and extends landwards resulting in some additional deepening of the section (see Figure 7).

Collectively these findings suggest that over the short-term (decades) the estuary has the capacity to adjust and have little discernible impact on the observable morphology (at least in historic records). However, the potential transgression distance is estimated to increase substantially under the more rapid sea level rise scenario projected for this century and this may have more serious implications. Over the 
longer-term (centuries) this becomes even more likely. Studies of the open coast have shown that despite our best attempts to defend a particular shoreline, these have had minimal influence on erosion rates over timescales of a century or more (Clayton, 1989). Indeed, defending the coast would appear to act a bit like compressing a spring and then releasing it; as soon as the defences fail, the shoreface rapidly retreats to recover its equilibrium position within the tidal frame. Hence the long-term retreat rate is unchanged. Whilst this has a direct impact on the behaviour at the mouth, it also implies that a similar "recovery" might occur within the estuary should confining defences fail. Constraining the estuary at the high-water margin also has the effect of halting any warping-up of the surrounding flood plain. Again, the implication is that there would be a sudden increase in accommodation space and a period of catch-up, assuming the sediment supply remains available.

\section{Conclusions}

Marine transgression depends fundamentally on the rate of sea level rise. Estuaries located in river valleys are, however, constrained laterally and longitudinally. Their ability to adjust additionally depends on sediment supply and any other changes in the forcing conditions, notably tides and river flow. A simple morphokinematic model has been used to examine marine transgression of estuary systems in response to sea level rise. This considered different types of valley (short and steep, long and flat) and varying sizes of flood plain within the valley, as well as varying rates of sea level rise, sediment supply and tidal amplitude.

The quantitative estimates indicate that when the flood plain is included the sediment demand is higher and so the transgression distance is much larger. However, if the flood plain is smaller or the system is constrained, the distances are smaller but the system becomes much more sensitive to changes in the rate of sea level rise, or 
changes in sediment supply (assuming, of course, that the boundary conditions remain constant). The important role of constraints, especially geological constraints, have already been highlighted by Allen (1990) and the model was able to replicate the observed "necking" when non-erodible sills are introduced into the model.

The important interaction of sea level rise and sediment supply has also been demonstrated. Considering the estuary in isolation, there is a clear dependency on the amount of sediment available. However, how the system evolves will also depend on what happens on the open coast. Preliminary results suggest that the transgression distance in estuaries with limited flood plains are likely to be similar in order of magnitude to the rate at which the open coast shoreline retreats. As the extent of the flood plain increases, there is the potential for the rate of transgression of the estuary to be faster than that of the shoreline, leading to an extension in length at the seaward end; although the overall length will also depend on the slope of the river valley at the tidal limit.

Given that many estuaries and open coasts are now defended, the influence of such constraints may have important consequences. Over the short-term (decades) the implications are not significant but potentially increase if the predicted acceleration in the rate of sea level rise occurs over the remainder of this century. However, over the medium to long-term, marine transgression may prompt a period of rapid "catch-up". Where flood plains have been defended and so starved of sediment, they will progressively become lower than the high-water level of the estuary. Should the defences fail, there will be an immediate increase in accommodation space and hence demand for sediment. The timescale for readjustment will depend on the availability of sediment and the prevailing rate of sea level rise (and hence ever-increasing accommodation space). 
The model is therefore instructive in terms of identifying the scale of changes that might be expected. Further work is needed to explore the form of incised river valleys and the extent of their flood plains, for a range of systems. This will then provide a clearer indication on the extent to which systems can adjust, or whether existing and future infrastructure developments are simply building a "coiled spring" which at some point will have to be released. In addition, some more detailed work using processbased models (flow, sediment transport and bed updating) that include bank erosion and sedimentation on the surrounding flood plain would further inform our understanding of marine transgression.

\section{Acknowledgement}

This study is supported by the National Natural Science Foundation of China (NSFC, Grant Nos. 41976156, 51620105005), and the Natural Science Foundation of Jiangsu Province (Grant No. BK20200077).

\section{Data Availability}

This is a theoretical modelling study and the relevant parameters are defined in the paper and SI. The model code is being prepared for release and will be available at www.coastalsea.uk. In the interim please contact the corresponding author.

\section{Conflict of Interest}

None. 


\section{References}

Allen, J.R.L., 1990. The Severn Estuary of southwest Britain: its retreat under marine transgression, and fine sediment regime. Sedimentary Geology, 66(1-2), 13-28.

Ardies, G.W., Dalrymple, R.W., Zaitlin, B.A., 2002. Controls on the Geometry of Incised Valleys in the Basal Quartz Unit (Lower Cretaceous), Western Canada Sedimentary Basin. Journal of Sedimentary Research, 72(5), 602-618. [10.1306/032101720602]

Avoine, J., 1987. Sediment exchanges between the Seine estuary and its adjacent shelf. Journal of the Geological Society, 144(1), 135-148. [10.1144/gsjgs.144.1.0135]

Bamunawala, J., Dastgheib, A., Ranasinghe, R., van der Spek, A., Maskey, S., Murray, A.B., Duong, T.M., Barnard, P.L., Sirisena, T.A.J.G., 2020. A Holistic Modeling Approach to Project the Evolution of Inlet-Interrupted Coastlines Over the 21st Century. Frontiers in Marine Science, 7. [10.3389/fmars.2020.00542]

Brückner, M.Z.M., Schwarz, C., Dijk, W.M., Oorschot, M., Douma, H., Kleinhans, M.G., 2019. Salt Marsh Establishment and Eco-Engineering Effects in Dynamic Estuaries Determined by Species Growth and Mortality. Journal of Geophysical Research: Earth Surface, 124(12), 2962-2986. [10.1029/2019jf005092]

Bruun, P., 1962. Sea level rise as a cause of shore erosion. Journal of Waterways and Harbours Division, ASCE, 88, 117-130.

Cai, H.Y., Savenije, H.H.G., Jiang, C., 2014. Analytical approach for predicting fresh water discharge in an estuary based on tidal water level observations. Hydrol Earth Syst Sc, 18(10), 41534168.

Clayton, K.M., 1989. Sediment Input from the Norfolk Cliffs, Eastern England - A Century of Coast Protection and Its Effect. Journal of Coastal Research, 5(3), 433-442.

Coco, G., Zhou, Z., van Maanen, B., Olabarrieta, M., Tinoco, R., Townend, I., 2013. Morphodynamics of tidal networks: advances and challenges. Marine Geology, 346, 1-16.

Dalrymple, R.W., 2006. Incised valleys in time and space: an introduction to the volume and an examination of the controls on valley formation. In: R.W. Dalrymple, D.A. Leckie, R.W. Tillman (Eds.), Incised valleys in time and space. Tulsa, Okla. : Society for Sedimentary Geology c2006., Tulsa, Okla., pp. 5-14.

Dalrymple, R.W., Boyd, R., Zaitlin, B.A., 1994. Incised-valley systems : origin and sedimentary sequences. Tulsa, Okla. : SEPM Society for Sedimentary Geology 1994., Tulsa, Okla.

Dalrymple, R.W., Leckie, D.A., Tillman, R.W., Sepm, 2006. Incised valleys in time and space. Tulsa, Okla. : Society for Sedimentary Geology c2006., Tulsa, Okla.

Davies, G., Woodroffe, C.D., 2010. Tidal estuary width convergence: Theory and form in North Australian estuaries. Earth Surface Processes and Landforms, 35(7), 737-749.

DiLorenzo, J.L., 1988. The overtide and filtering response of small inlet/bay systems. In: D.G. Aubrey, L. Weishar (Eds.), Hydrodynamics and sediment dynamics of tidal inlets. Lecture Notes on Coastal and Estuarine Studies. Springer-Verlag, New York, pp. 24-53.

Dronkers, J., 1986. Tidal asymmetry and estuarine morphology. Netherlands Journal of Sea Research, 20(2/3), 117-131.

Du, J., Shen, J., Zhang, Y.J., Ye, F., Liu, Z., Wang, Z., Wang, Y.P., Yu, X., Sisson, M., Wang, H.V., 2018. Tidal Response to Sea-Level Rise in Different Types of Estuaries: The Importance of Length, Bathymetry, and Geometry. Geophysical Research Letters, 45(1), 227-235. [10.1002/2017gl075963]

Haldane, A.G., May, R.M., 2011. Systemic risk in banking ecosystems. Nature, 469(7330), 351-355. Heap, A.D., Bryce, S., Ryan, D.A., 2004. Facies evolution of Holocene estuaries and deltas: a largesample statistical study from Australia. Sedimentary Geology, 168(1-2), 1-17. [http://dx.doi.org/10.1016/j.sedgeo.2004.01.016]

Heap, A.D., Nichol, S.L., 1997. The influence of limited accommodation space on the stratigraphy of an incised-valley succession: Weiti River estuary, New Zealand. Marine Geology, 144(1), 229-252. [https://doi.org/10.1016/S0025-3227(97)00107-2] 
Hume, T.M., Herdendorf, C.E., 1988. A geomorphic classification of estuaries and its application to coastal resource management. Journal of Ocean and Shoreline Management, 11, 249-274.

Idier, D., Paris, F., Cozannet, G.L., Boulahya, F., Dumas, F., 2017. Sea-level rise impacts on the tides of the European Shelf. Continental Shelf Research, 137, 56-71. [10.1016/j.csr.2017.01.007]

Kennedy, V.S., 1984. The Estuary as a Filter. Academic Press, New York.

Leuven, J., Verhoeve, S., van Dijk, W., Selaković, S., Kleinhans, M., 2018. Empirical Assessment Tool for Bathymetry, Flow Velocity and Salinity in Estuaries Based on Tidal Amplitude and Remotely-Sensed Imagery. Remote Sensing, 10(12). [10.3390/rs10121915]

Leuven, J.R.F.W., Pierik, H.J., Vegt, M.v.d., Bouma, T.J., Kleinhans, M.G., 2019. Sea-level-rise-induced threats depend on the size of tide-influenced estuaries worldwide. Nature Climate Change, 9(12), 986-992. [10.1038/s41558-019-0608-4]

Murray, A.B., 2007. Reducing model complexity for explanation and prediction. Geomorphology, 90(3-4), 178-191.

O'Connor, B.A., 1987. Short and long term changes in estuary capacity. Journal of the Geological Society, 144(1), 187-195. [10.1144/gsjgs.144.1.0187]

Olabarrieta, M., Geyer, W.R., Coco, G., Friedrichs, C.T., Cao, Z., 2018. Effects of Density-Driven Flows on the Long-Term Morphodynamic Evolution of Funnel-Shaped Estuaries. Journal of Geophysical Research: Earth Surface, 123(11), 2901-2924. [10.1029/2017jf004527]

Pethick, J.S., 1994. Estuaries and wetlands: function and form. In: R.A. Falconer, P. Goodwin (Eds.). Wetland Management. Thomas Telford, pp. 75-87.

Pickering, M.D., Horsburgh, K.J., Blundell, J.R., Hirschi, J.J.M., Nicholls, R.J., Verlaan, M., Wells, N.C., 2017. The impact of future sea-level rise on the global tides. Continental Shelf Research, 142, 50-68. [10.1016/j.csr.2017.02.004]

Pickering, M.D., Wells, N.C., Horsburgh, K.J., Green, J.A.M., 2012. The impact of future sea-level rise on the European Shelf tides. Continental Shelf Research, 35, 1-15.

Posamentier, H.W., Walker, R.G., 2006. Facies models revisited. Tulsa, Okla. : Society for Sedimentary Geology c2006., Tulsa, Okla.

Pye, K., Blott, S.J., 2014. The geomorphology of UK estuaries: The role of geological controls, antecedent conditions and human activities. Estuarine, Coastal and Shelf Science, 150, 196-214. [10.1016/j.ecss.2014.05.014]

Rees, J.G., 2006. Sea-level, topographical and sediment supply controls on Holocene sediment composition in the Humber Estuary. Phil.Trans.R.Soc.Lond.A., 364, 993-1008.

Rees, J.G., Newsham, R., Evans, C.D.R., 2006. Modelling Holocene coastal erosion and sediment supply in the western North Sea. Geological Society of America(Special Publication).

Rees, J.G., Ridgway, J., Ellis, S., Knox, R.W.O., Newsham, R., Parkes, A., 2000. Holocene sediment storage in the Humber Estuary. In: I. Shennan, J.E. Andrews (Eds.), Holocene Land-ocean interaction and environmental change around the North Sea. Special Publications 166. Geological Society, London, pp. 119-143.

Rossington, K., Nicholls, R.J., Knaapen, M.A.F., Wang, Z.B., 2007. Morphological Behaviour of UK Estuaries under Conditions of Accelerating Sea Level Rise. In: C.M. Dohmen-Janssen, S.J.M.H. Hulscher (Eds.), RCEM2007. River, Coastal and Estuarine Morphodynamics. Taylor \& Francis. [https://doi.org/10.1201/noe0415453639-c16]

Roy, P.S., 1984. New South Wales estuaries: their origin and evolution. Coastal Geomorphology in Australia, 5. Academic Press Australia, Sidney.

Savenije, H.H.G., 2015. Prediction in ungauged estuaries: An integrated theory. Water Resources Research, 51(4), 2464-2476. [10.1002/2015wr016936]

Scully, M.E., Friedrichs, C.T., 2007. Sediment pumping by tidal asymmetry in a partially mixed estuary. Journal of Geophysical Research, 112(C07028).

Seminara, G., Lanzoni, S., Tambroni, N., Toffolon, M., 2010. How long are tidal channels? Journal of Fluid Mechanics, 643, 479-494.

Shi, Z., Lamb, H.F., 1991. Post-glacial sedimentary evolution of a microtidal estuary, Dyfi Estuary, west Wales, U.K. Sedimentary Geology, 73(3), 227-246. [https://doi.org/10.1016/00370738(91)90086-S] 
Stive, M.J.E., Wang, Z.B., 2003. Morphodynamic modeling of tidal basins and coastal inlets. In: V.C. Lakhan (Ed.), Advances in Coastal Modeling. Elsevier Sciences, pp. 367-392.

Townend, I.H., 2010. An exploration of equilibrium in Venice Lagoon using an idealised form model. Continental Shelf Research, 30(8), 984-999. [https://doi.org/10.1016/j.csr.2009.10.012]

Townend, I.H., 2012. The estimation of estuary dimensions using a simplified form model and the exogenous controls. Earth Surface Processes and Landforms, 37, 1573-1583. [http://dx.doi.org/10.1002/esp.3256]

Townend, I.H., McLaren, P., 1988. Anglian coastal management atlas, Swindon, UK.

Townend, I.H., Pethick, J., 2002. Estuarine flooding and managed retreat. Phil.Trans.R.Soc.Lond.A, 360(1796), 1477-1495.

Townend, I.H., Wang, Z.B., Rees, J.G., 2007. Millennial to annual volume changes in the Humber Estuary. Proc.R.Soc.A, 463, 837-854. [https://doi.org/10.1098/rspa.2006.1798]

Townend, I.H., Wang, Z.B., Stive, M.J.E., Zhou, Z., 2016a. Development and extension of an aggregated scale model: Part 1 - Background to ASMITA. China Ocean Engineering, 30(4), 482-504. [https://doi.org/10.1007/s13344-016-0030-x]

Townend, I.H., Wang, Z.B., Stive, M.J.E., Zhou, Z., 2016b. Development and extension of an aggregated scale model: Part 2 - Extensions to ASMITA. China Ocean Engineering, 30(5), 651-670. [https://doi.org/10.1007/s13344-016-0042-6]

Townend, I.H., Whitehead, P.A., 2003. A preliminary net sediment budget for the Humber Estuary. The Science of the Total Environment, 314-316, 755-767.

Uncles, R.J., Easton, A.E., Griffiths, M.L., Harris, C., Howland, R.J.M., King, R.S., Morris, A.W., Plummer, D.H., 1999. Seasonality of the turbidity maximum in the Humber-Ouse estuary. Marine Pollution Bulletin, 37(3), 206-215.

van Goor, M.A., Zitman, T.J., Wang, Z.B., Stive, M.J.F., 2003. Impact of sea-level rise on the morphological equilibrium state of tidal inlets. Marine Geology, 202, 211-227. [https://doi.org/10.1016/s0025-3227(03)00262-7]

van Maren, D.S., Winterwerp, J.C., 2013. The role of flow asymmetry and mud properties on tidal flat sedimentation. Continental Shelf Research, 60, S71-S84. [10.1016/j.csr.2012.07.010]

Wang, Z.B., Townend, I., Stive, M., 2020. Aggregated morphodynamic modelling of tidal inlets and estuaries. Water Science and Engineering, 13(1), 1-13. [https://doi.org/10.1016/j.wse.2020.03.004]

Wang, Z.B., Townend, I.H., 2012. Influence of the nodal tide on the morphological response of estuaries. Marine Geology, 291-294, 73-82. [https://doi.org/10.1016/i.margeo.2011.11.007]

Wingfield, R., Evans, C., 1998. The significance of the shoreface ramp for coastal development: Holderness, eastern England, UK. Littoral '98. Suport Serveis SA, Barcelona, pp. 1-17.

Winterwerp, J.C., 2006. The transport of fine sediment in the Humber Estuary. Z3040, Delft, Netherlands.

Woodroffe, C.D., Chappell, J., Thorn, B.G., Wallensky, E., 1989. Depositional model of a macrotidal estuary and floodplain, South Alligator River, Northern Australia. Sedimentology, 36, 737756.

Zaitlin, B.A., Dalrymple, R.W., Boyd, R., Dalrymple, R.W., Boyd, R., Zaitlin, B.A., 1994. The Stratigraphic Organization of Incised-Valley Systems Associated with Relative Sea-Level Change, Incised-Valley Systems: Origin and Sedimentary Sequences. SEPM Society for Sedimentary Geology, pp. 0.

Zhao, K., Gong, Z., Xu, F., Zhou, Z., Zhang, C.K., Perillo, G.M.E., Coco, G., 2019. The Role of Collapsed Bank Soil on Tidal Channel Evolution: A Process-Based Model Involving Bank Collapse and Sediment Dynamics. Water Resources Research, 55(11), 9051-9071. [10.1029/2019wr025514] 
Zhou, Z., Chen, L., Tao, J., Gong, Z., Guo, L., Wegen, M., Townend, I., Zhang, C., 2020. The role of salinity in fluvio-deltaic morphodynamics: A long-term modelling study. Earth Surface Processes and Landforms, 45(3), 590-604. [https://doi.org/10.1002/esp.4757]

Zhou, Z., Coco, G., Townend, I., Gong, Z., Wang, Z.B., Zhang, C.K., 2018. On the stability relationships between tidal asymmetry and morphologies of tidal basins and estuaries. Earth Surface Processes and Landforms, 43(9), 1943-1959. [https://doi.org/10.1002/esp.4366]

Zhou, Z., Coco, G., Townend, I., Olabarrieta, M., van der Wegen, M., Gong, Z., D'Alpaos, A., Gao, S., Jaffe, B.E., Gelfenbaum, G., He, Q., Wang, Y.P., Lanzoni, S., Wang, Z.B., Winterwerp, H., Zhang, C., 2017. Is "Morphodynamic Equilibrium" an oxymoron? Earth-Science Reviews, 165, 257-267. [https://doi.org/10.1016/i.earscirev.2016.12.002]

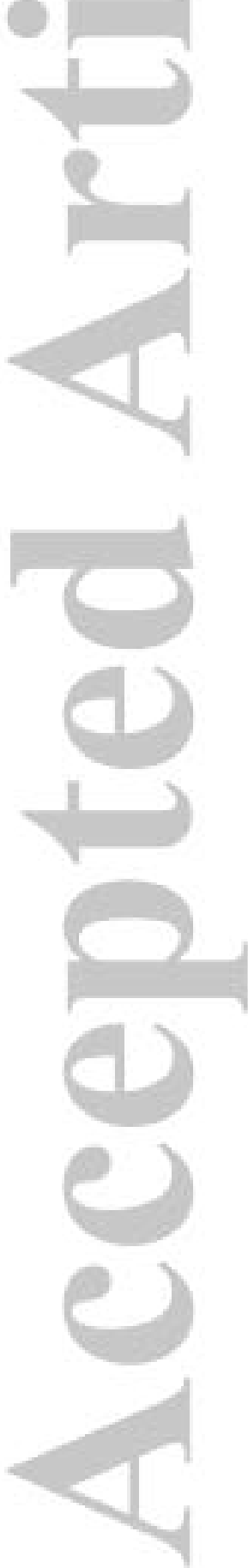




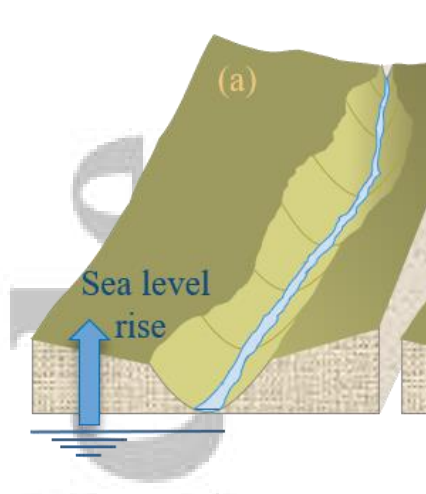

.

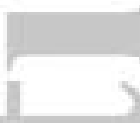

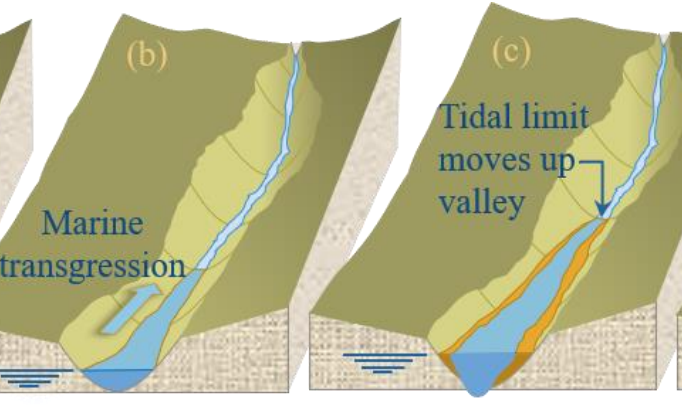

Potential erosion of basal Holocene surface

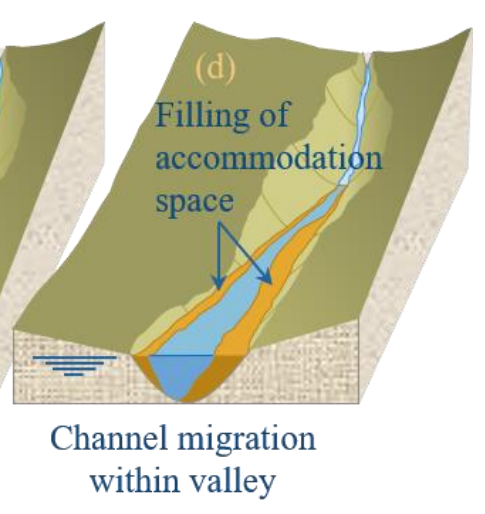

within valley

Figure 1 - Schematic of estuarine marine transgression. The plots depict (a) the preHolocene incised river valley, (b) the formation of the proto-estuary as sea level reaches the level of the section shown, (c) initial sediment infilling of excess accommodation space and increase in tidal prism as the estuary extends landwards, and $(d)$ continued sediment infilling, channel movement and the formation of a more extensive flood plain as sea level continues to rise. Note the shoreline is seaward of the channel shown in all cases but getting closer over time, such that the end section in plot (d) is close to the mouth of the estuary.

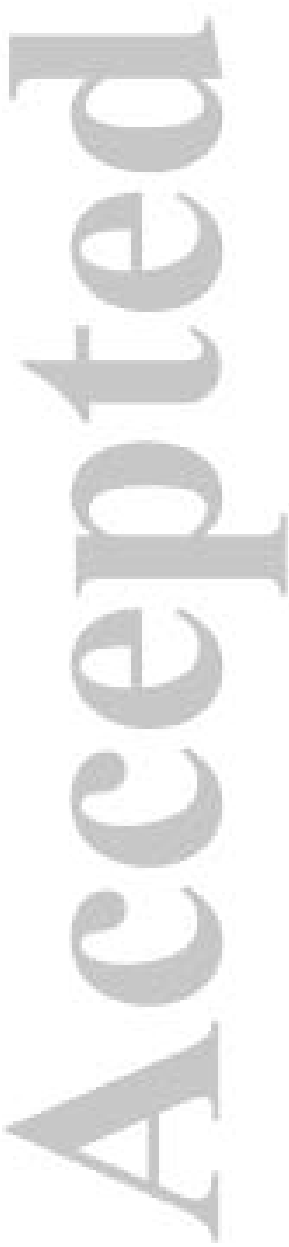

This article is protected by copyright. All rights reserved. 

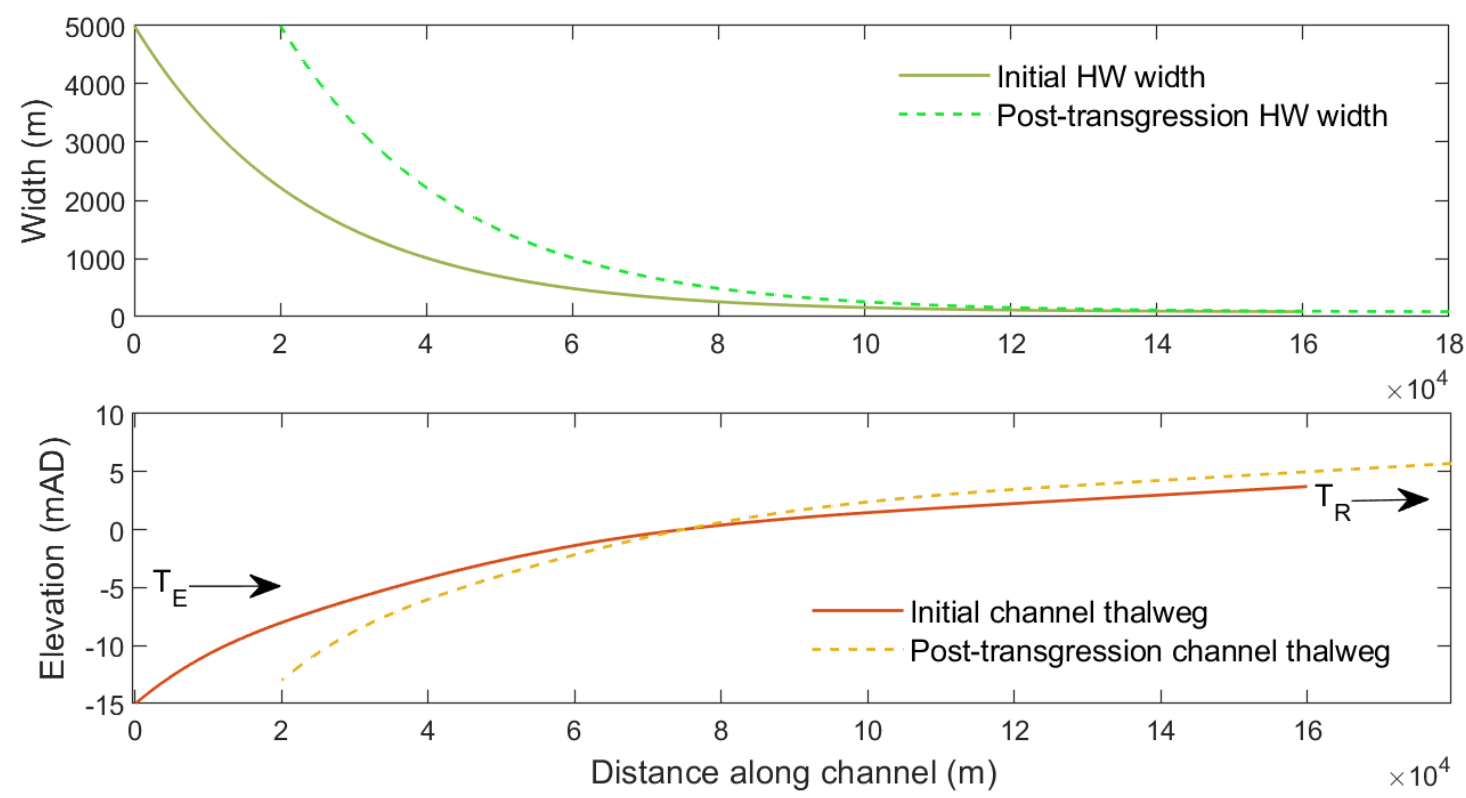

Figure 2 -Along channel change in width (upper plot) and thalweg bed level (lower plot). $T_{E}$ is the transgression distance of the estuary at the mouth, which may be different from the transgression distance of the open coast, $T_{C}$ (not shown) and $T_{R}$ is the transgression distance of the tidal limit.

This article is protected by copyright. All rights reserved. 


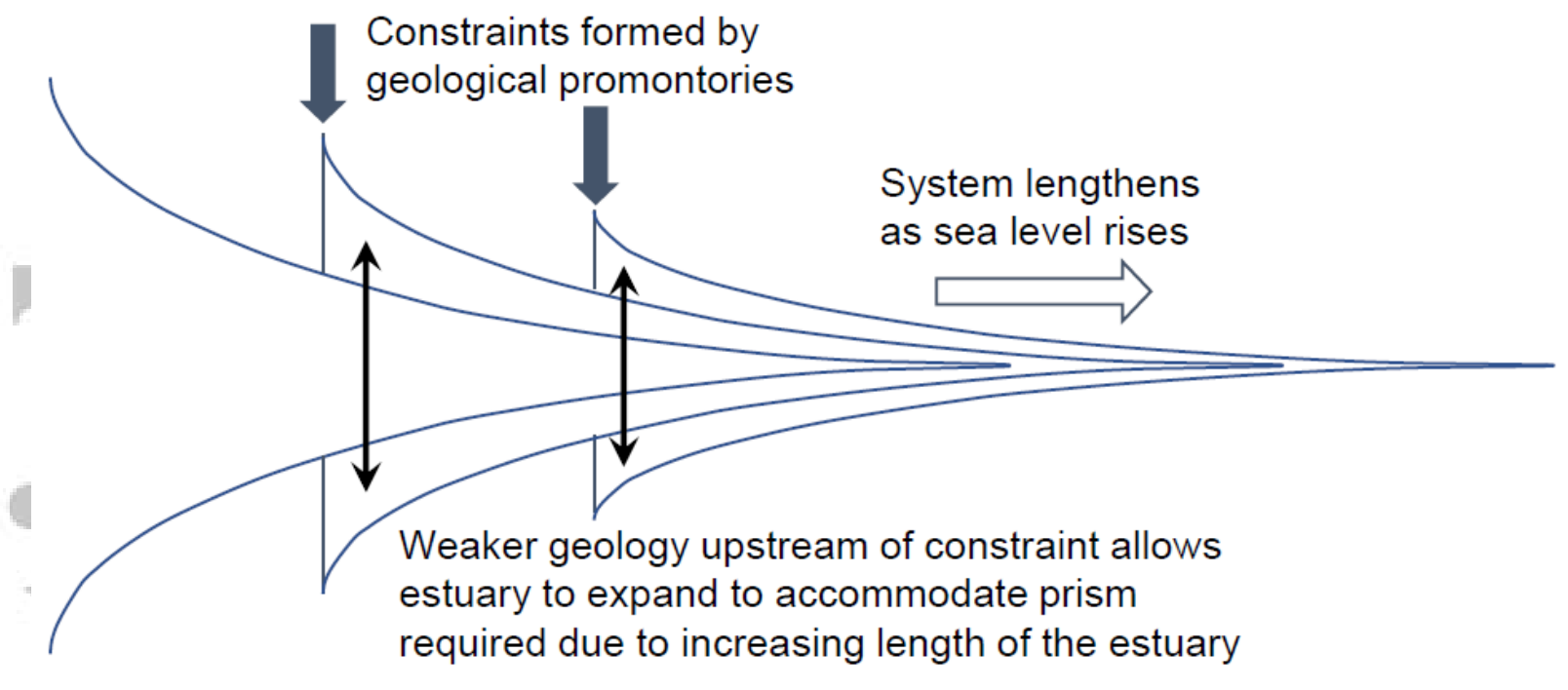

Figure 3- (a) Conceptual model for transgression with constraints proposed by Allen (1990)

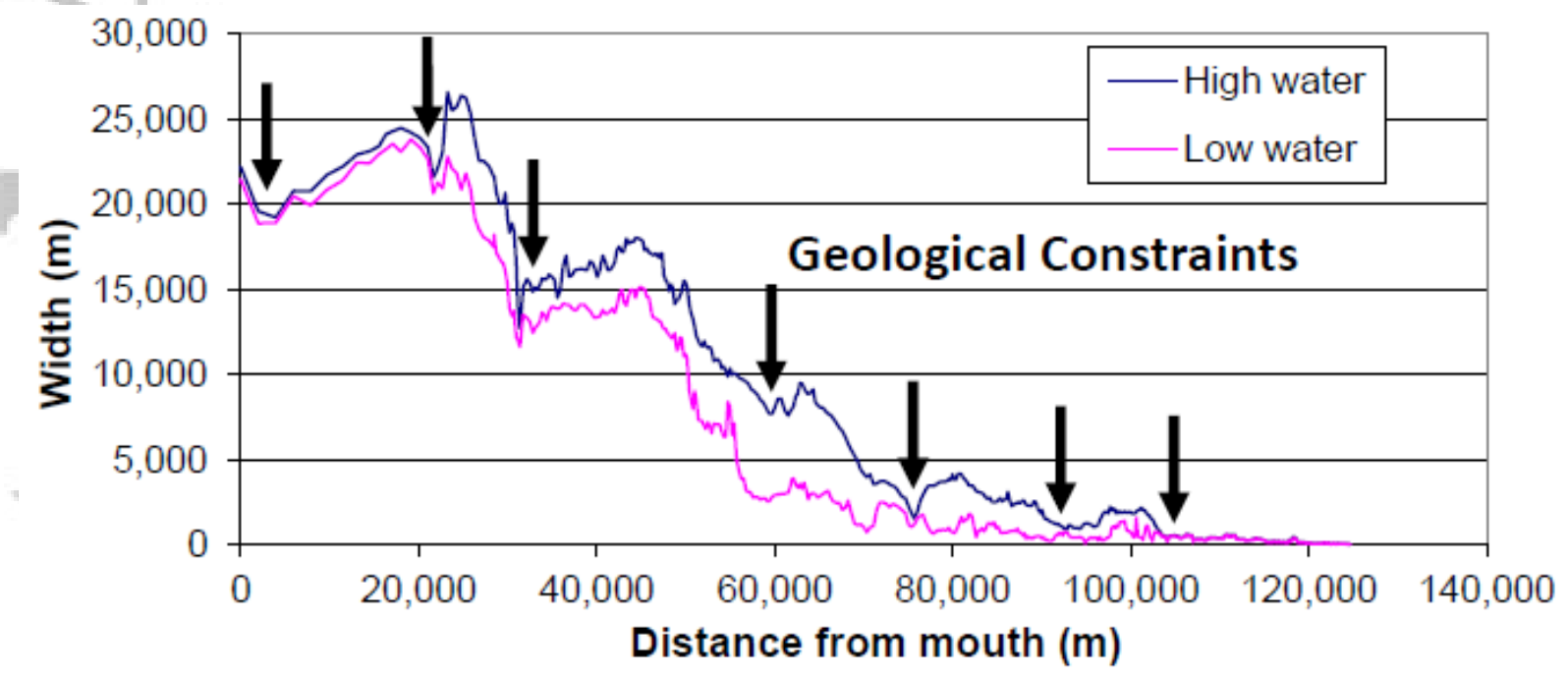

Figure 3 - (b) data from the Severn Estuary showing the impact of constraints on channel width. Distances start from a line between Aberthaw (Wales) and Minehead (England) and progress upstream.

Figure 3- (a) Conceptual model for transgression with constraints proposed by Allen (1990) and (b) data from the Severn Estuary showing the impact of constraints on channel width. Distances start from a line between Aberthaw (Wales) and Minehead (England) and progress upstream. 
(a) Channel Form

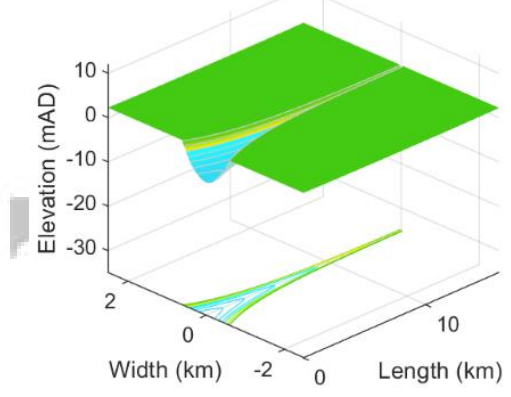

(b) Valley Form

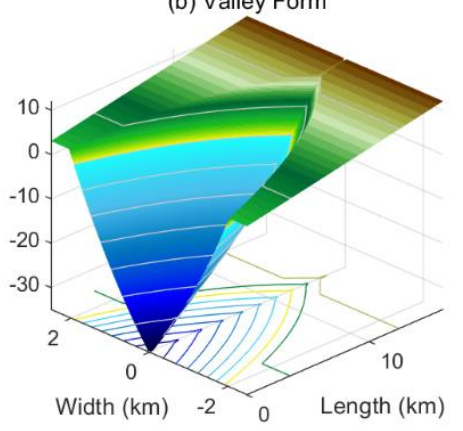

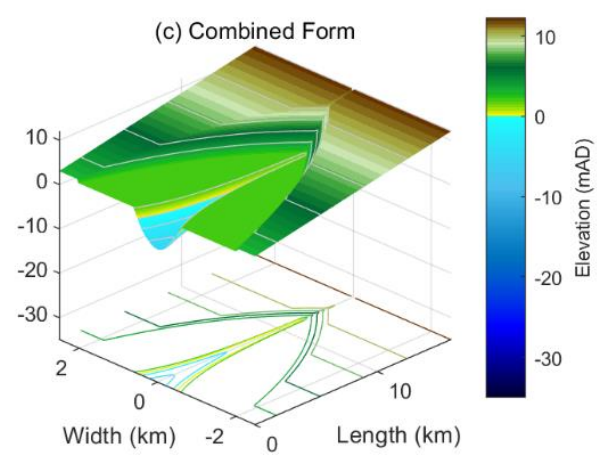

Width $(\mathrm{km}) \quad-2 \quad 0 \quad$ Length $(\mathrm{km})$

(i) Short, steep valley

(a) Channel Form

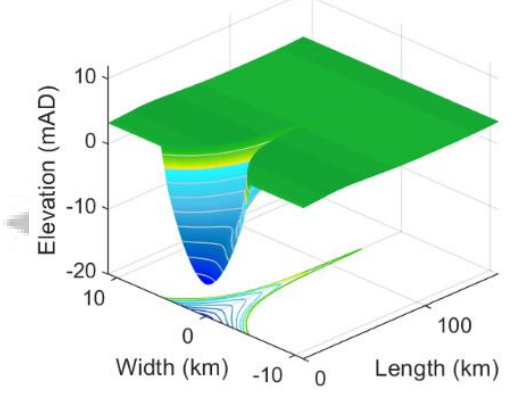

(b) Valley Form

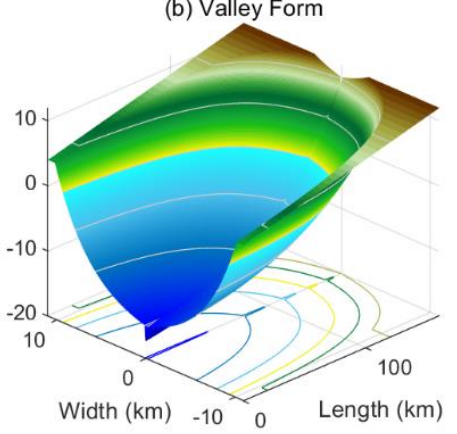

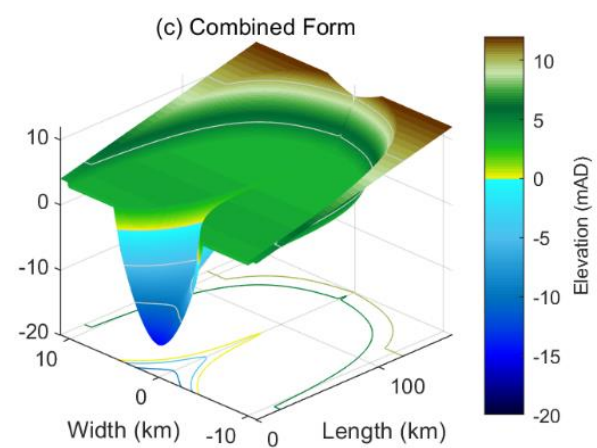

(ii) Long, steep valley

(a) Channel Form

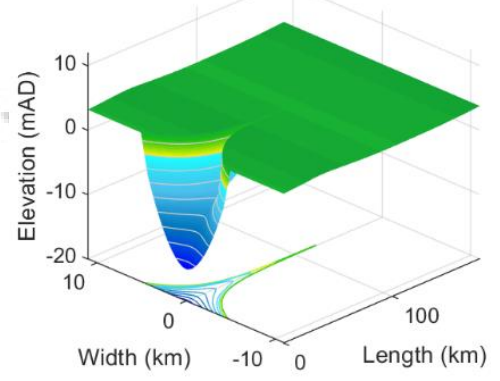

(b) Valley Form

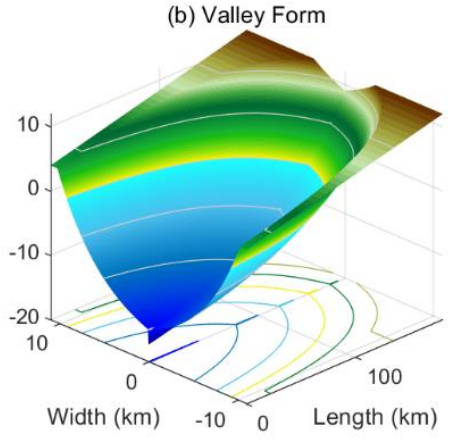

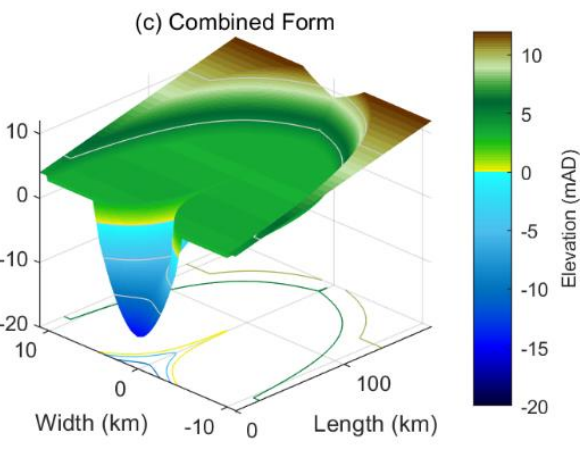

(iii) Long, flat valley

Figure 4 - illustration of the combination of an estuary form (a) and a valley form (b) to give an estuary and surrounding flood plain embedded in a valley (c). The three cases are shown for (i) a short, steep valley, (ii) a long, steep valley and (iii) a long flat valley.

This article is protected by copyright. All rights reserved. 


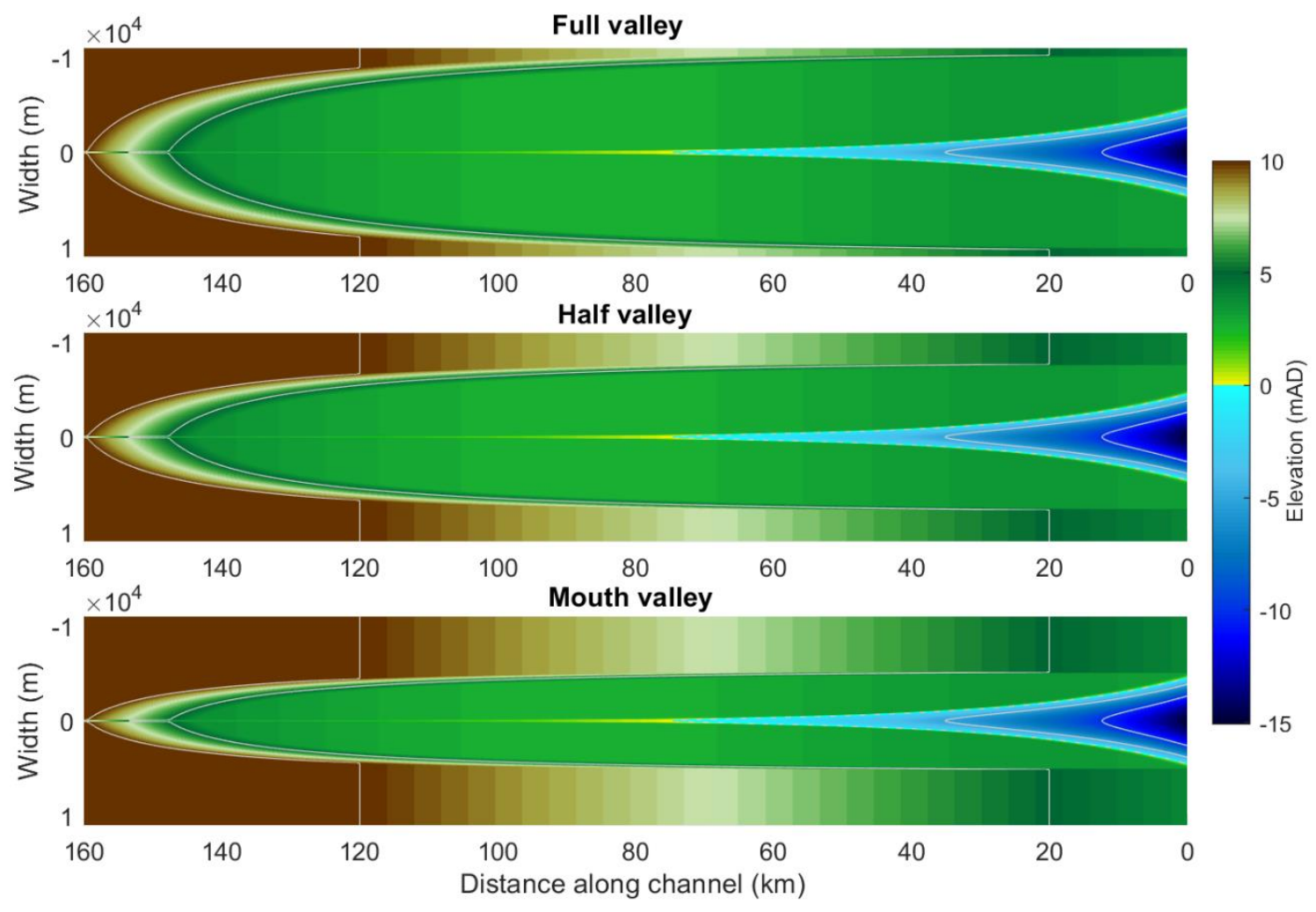

Figure 5-Plan view of the three valley configurations, for the long-steep valley case, with varying width at the mouth reducing the area of the surrounding flood plain and hence the available accommodation space

This article is protected by copyright. All rights reserved. 


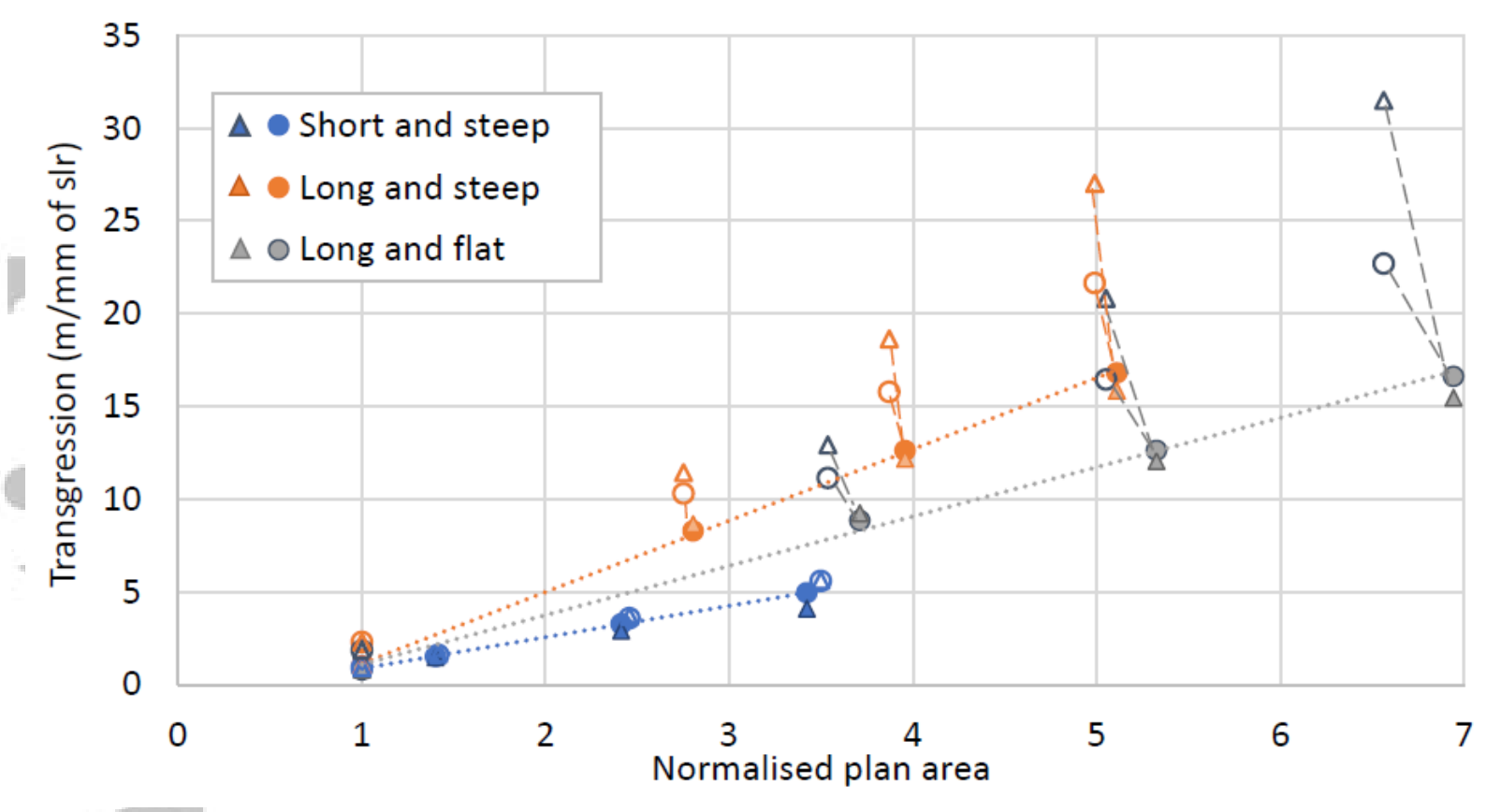

Figure 6-Transgression distance per $\mathrm{mm}$ of sea level rise for the 3 valleys as a function of plan areas normalised with respect to the estuary plan area at HW (NPA), varying from the no flood plain case (NPA=1, area is just the estuary at high water) to the full valley. The circle symbols are for a linear SLR of $0.2 \mathrm{~m}$ and the accelerating $S L R$ of $0.55 \mathrm{~m}$ are shown with triangle symbols. Filled symbols are results using the QDK model and open symbols are SK model results. The SK case is a translation of the initial estuary form, whereas the QDK case takes account of changes in water levels and any external sediment exchange. The dotted lines indicate the trend line for the QDK linear-slr case. Dashed lines link dynamic and static results for a given valley cases. Note that transgression in $\mathrm{m} / \mathrm{mm}$ of s/r can also be read as $\mathrm{km} / \mathrm{m}$ of s/r.

This article is protected by copyright. All rights reserved. 


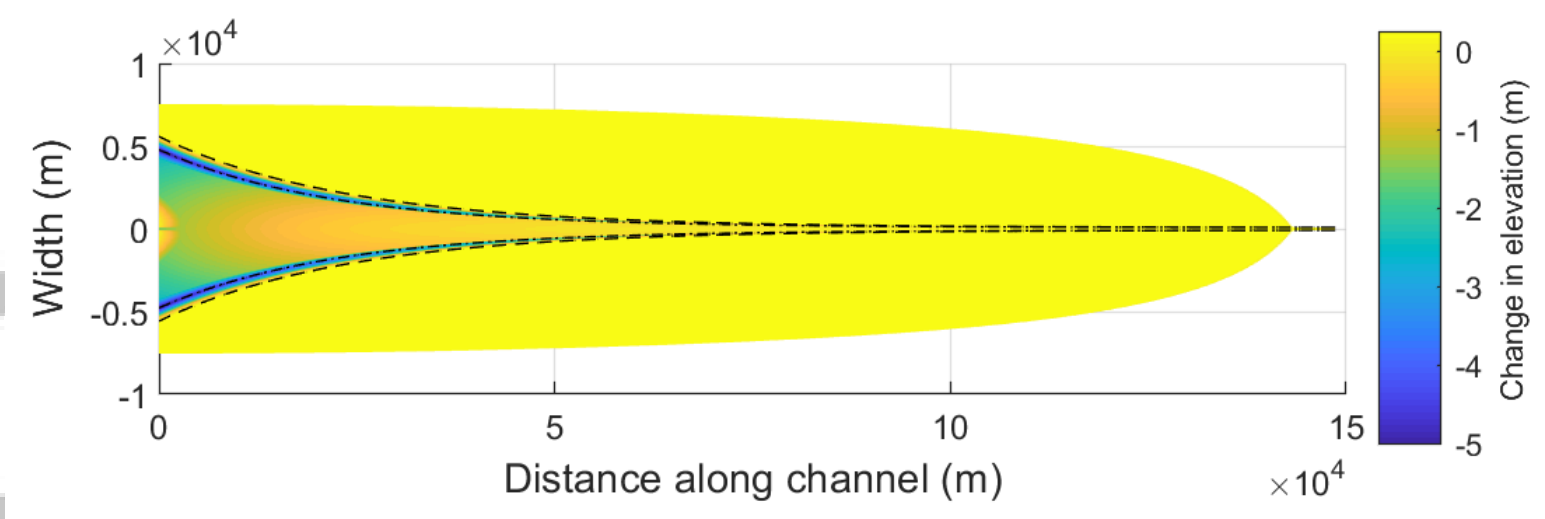

(a) plan view of difference plot

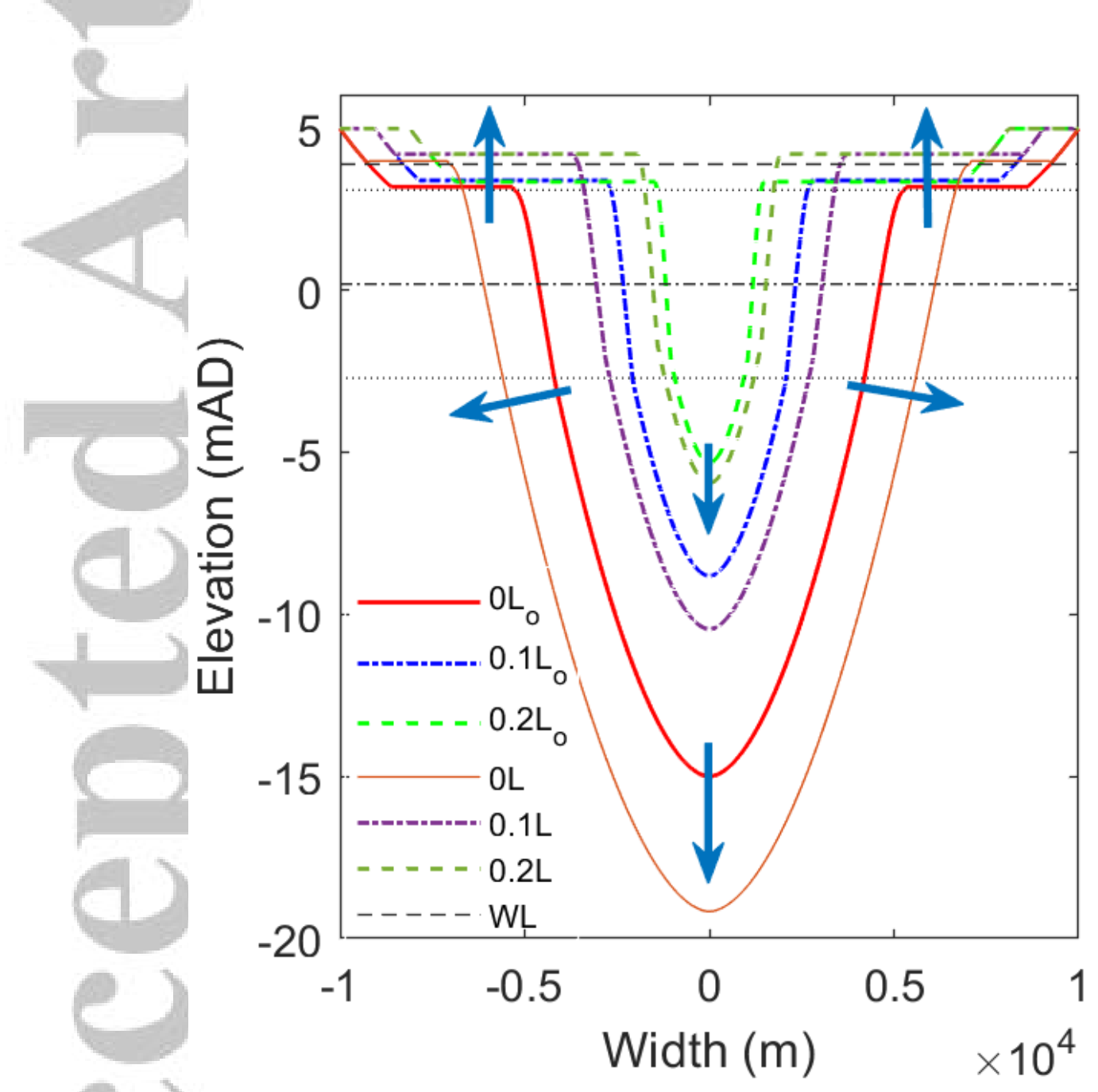

(b) including flood plain 


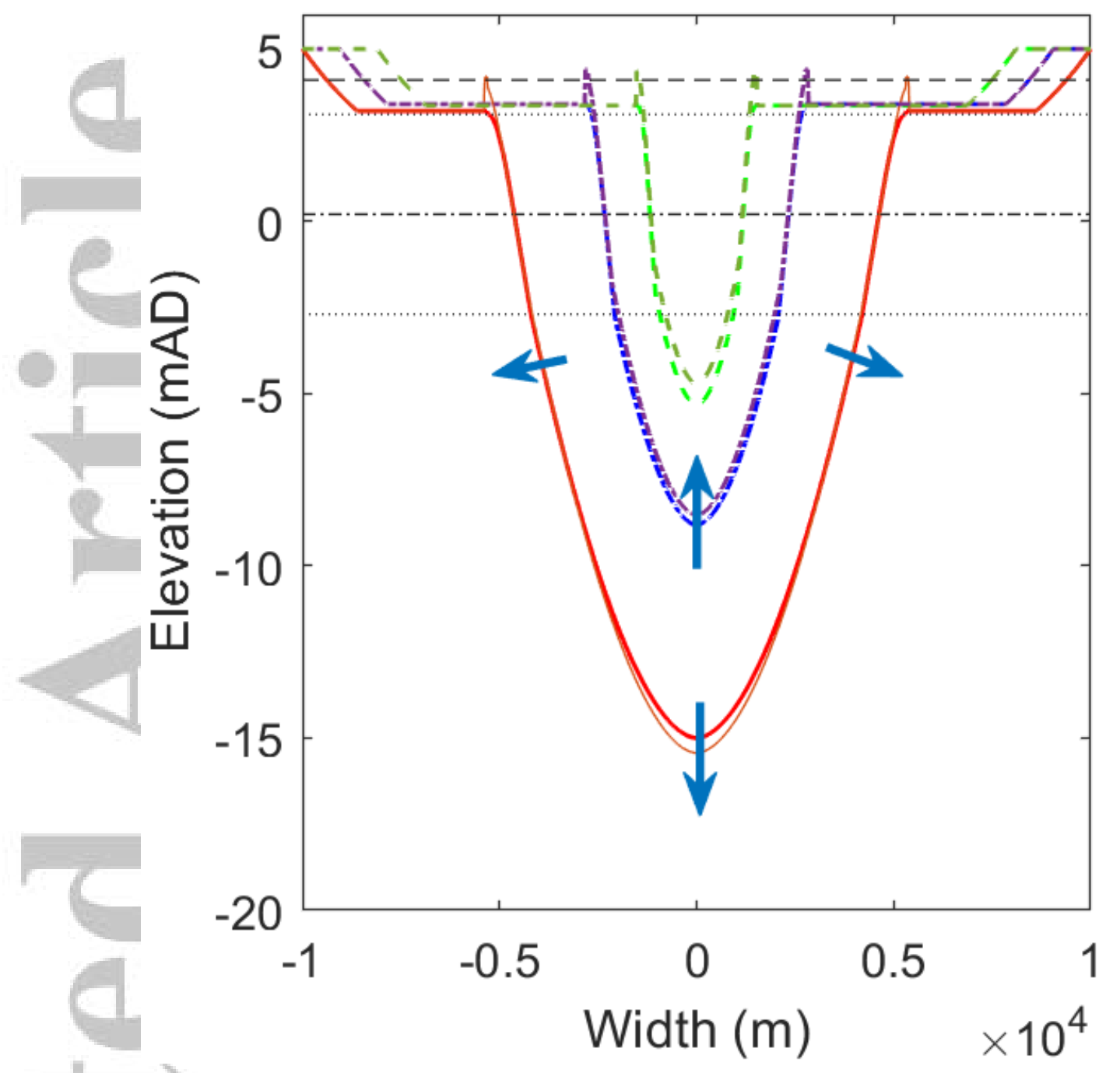

(c) excluding flood plain

Figure 7- (a) Difference plot between initial and final bathymetry for a $0.2 \mathrm{~m}$ rise in sea level. The dashed line indicates the high-water level after sea level rise. Plots (b) and (c) depict variations in channel cross sections taken at $0.0 \mathrm{~L}, 0.1 \mathrm{~L}$ and $0.2 \mathrm{~L}$ from the mouth, where $L$ is the estuary length. The subscript 'o' indicates the initial sections. The dashed horizontal lines are the mean tide level at the start of the run (dash-dot), high and low water at the start of the run (dot) and high water at the end of the run (dash). The arrows indicate the general direction of change in the section. In (c) the spikes at the high-water mark are due to deposition over a narrow width to exclude the flood plain.

This article is protected by copyright. All rights reserved. 


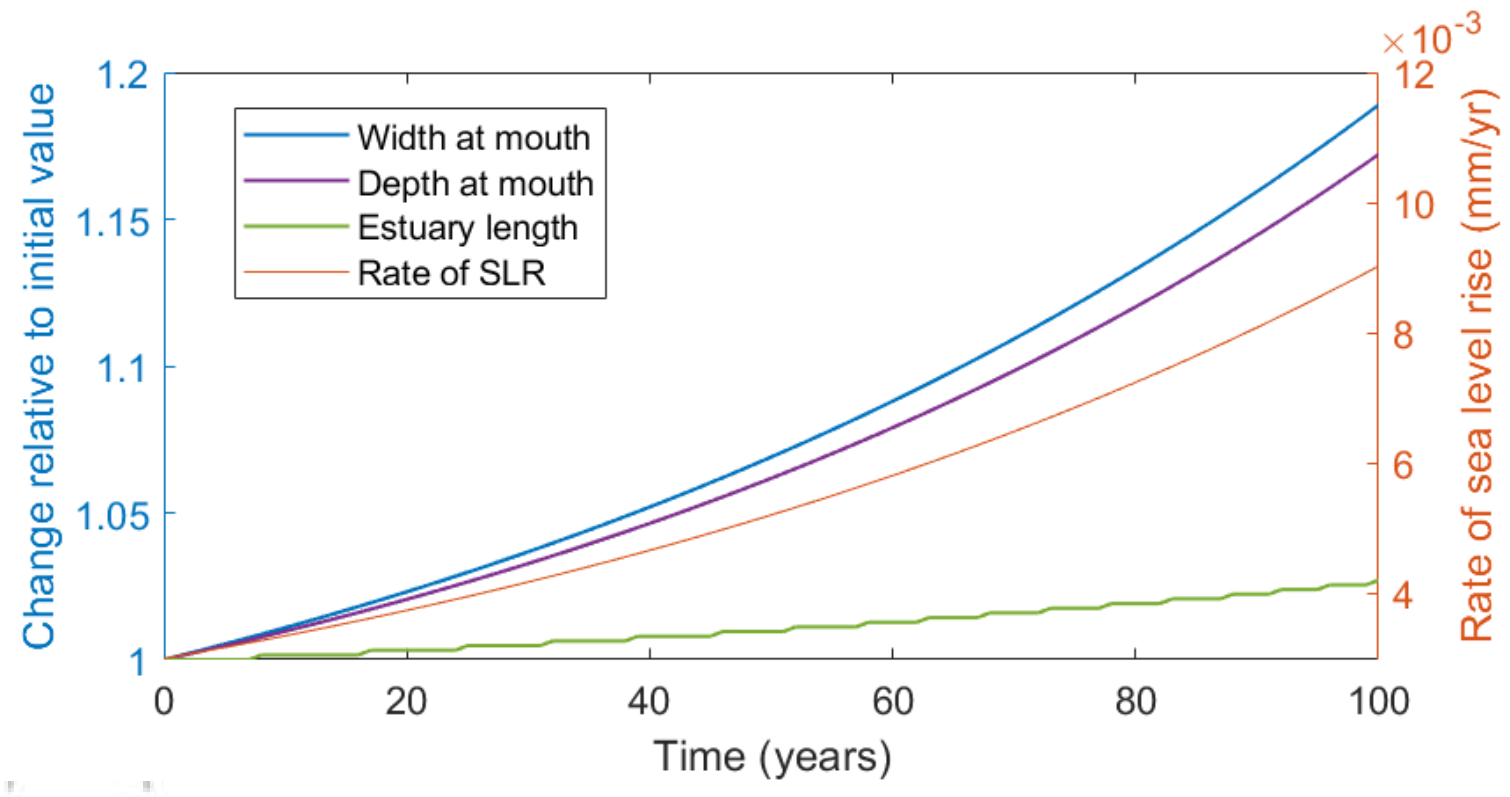

Figure 8 - Variation of width and depth at the mouth and estuary length under an accelerating rate of sea level rise. Values are relative to the initial dimensions. 


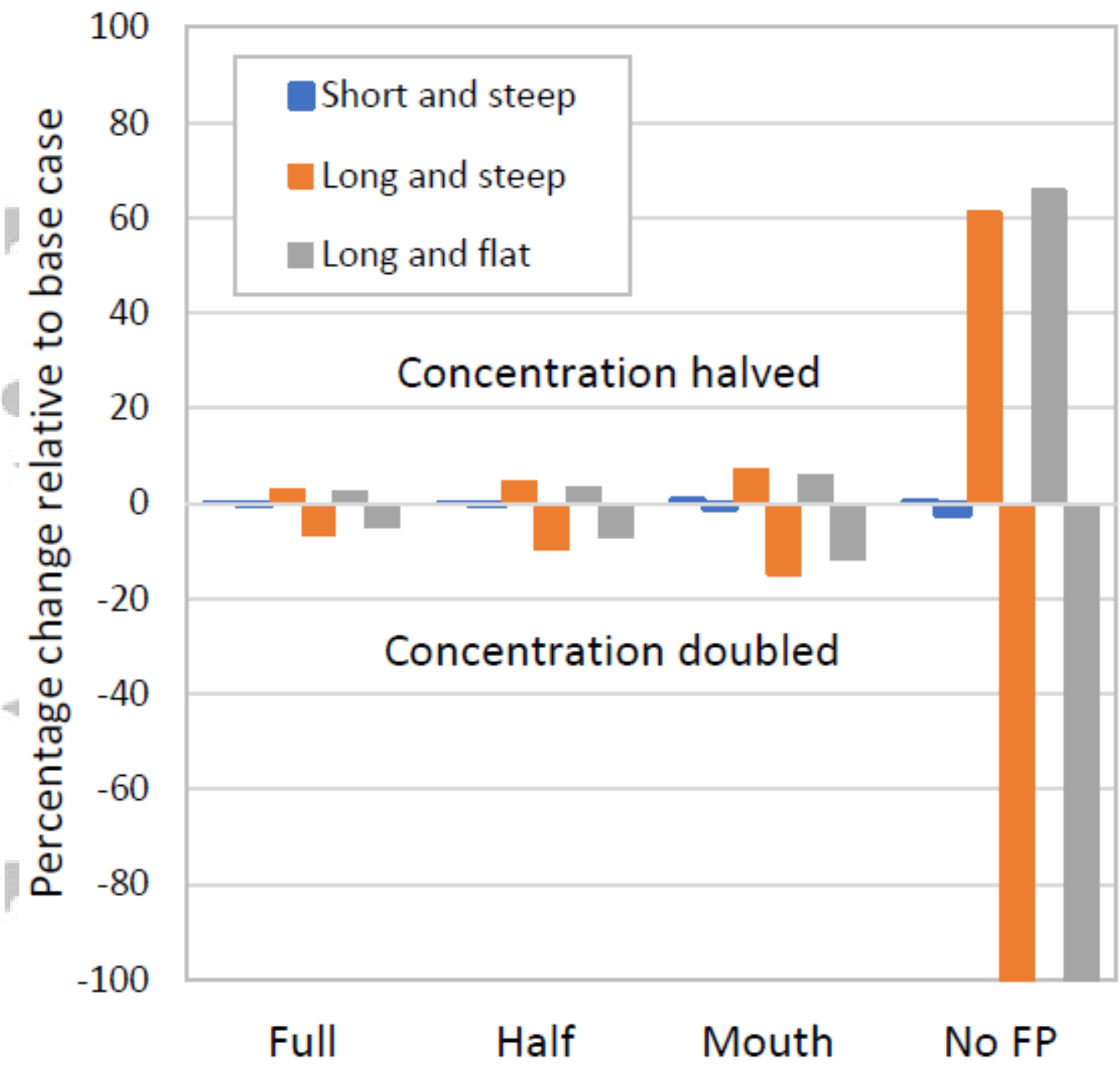

Figure 9-Percentage change in transgression distance relative to the base case with a linear s/r of $2 \mathrm{~mm} /$ year. In the no flood plain case (No FP), doubling the concentration supply to the long valleys is sufficient to allow them to warp-up in situ with zero transgression. 


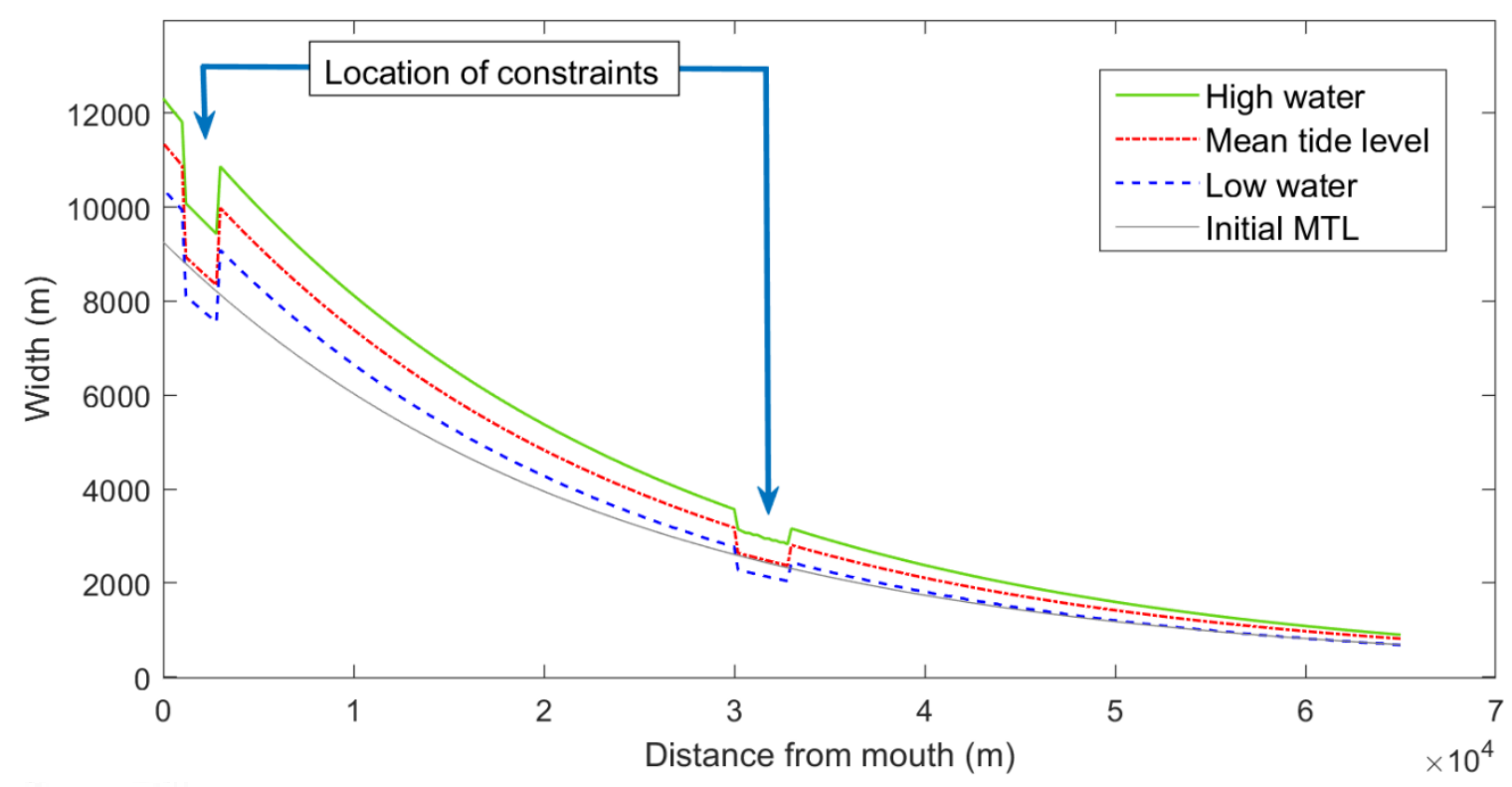

Figure 10 - Post-transgression estuary widths, with channel bed constraints between $1-3 \mathrm{~km}$ and $30-33 \mathrm{~km}$ from the mouth

This article is protected by copyright. All rights reserved. 


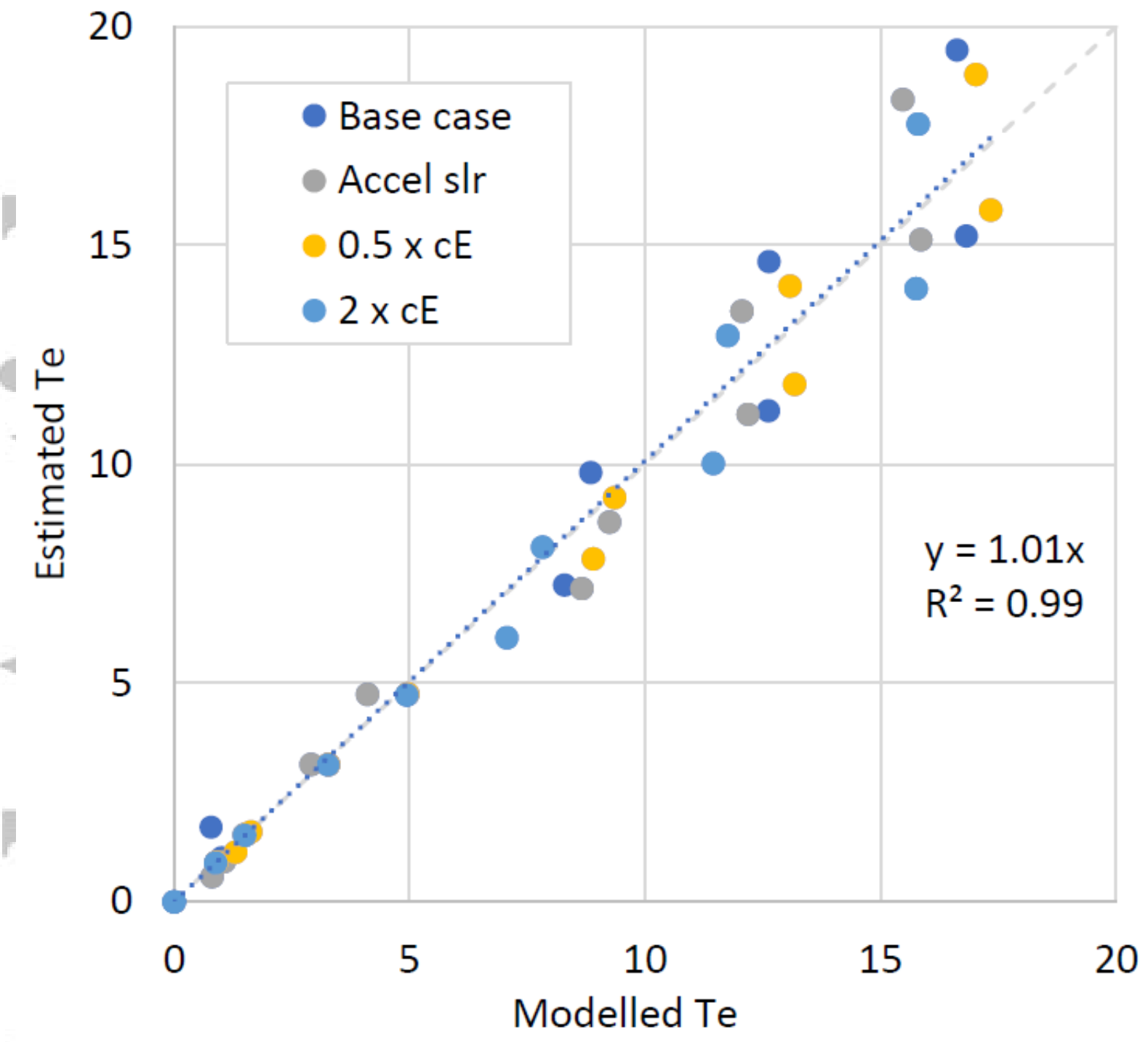

Figure 11 - Comparison of modelled transgression distances with values estimated using the empirical method. The base case uses a linear change of $0.2 \mathrm{~m}$, accelerated sir results in a change of $0.55 \mathrm{~m}$ and the sediment supply cases, $c E$ used half and double the concentration used in the base case. The dashed line is the 1:1 line and and the dotted line is the linear regression line for all data points and zero intercept. $A$ slope close to 1 indicates that there is little bias in the estimates. 


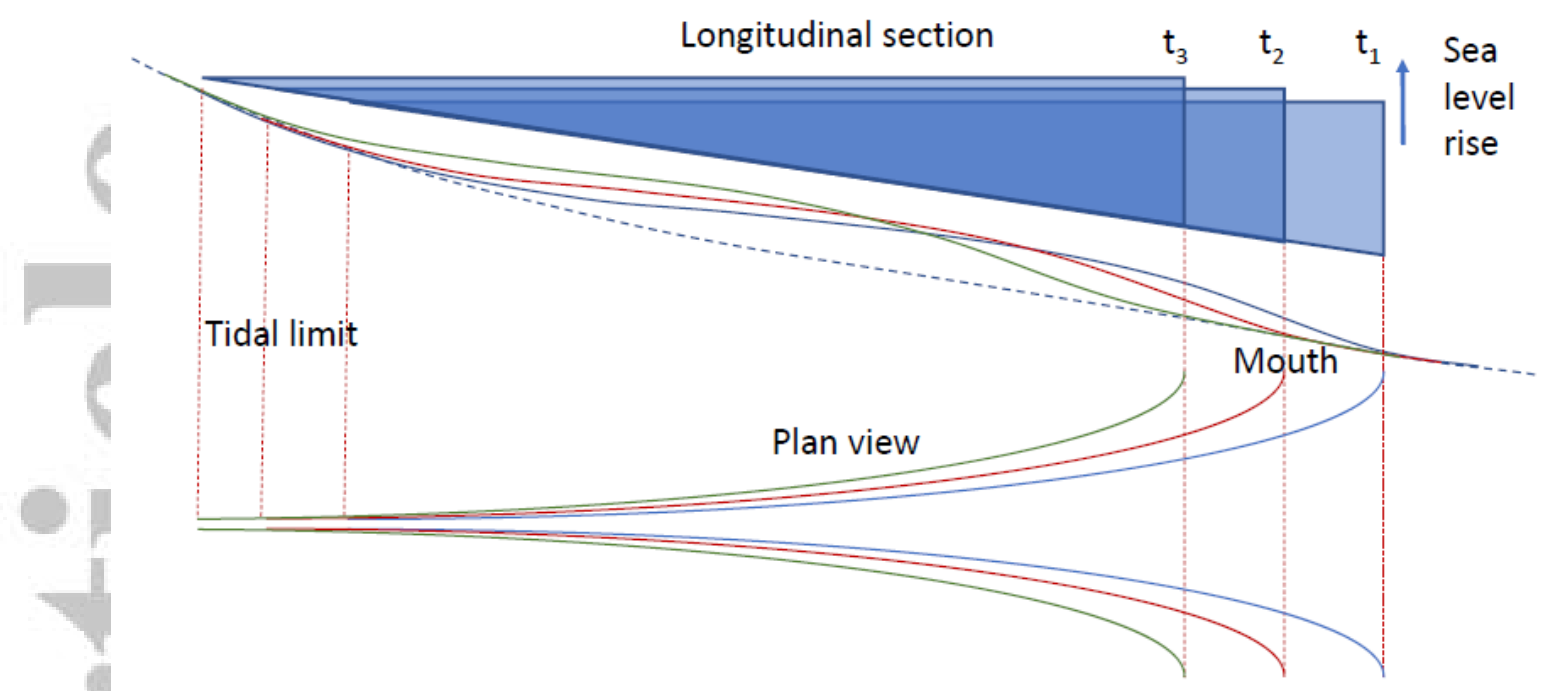

12(a) Rate of transgression of the estuary mouth and the estuary are of a similar magnitude. The estuary can maintain a similar (equilibrium) form in terms of rate of convergence, mouth width and depth. The length may change depending on the river valley slope at the tidal limit. The transgression slope of the shoreline and the slope of the relict estuary bed seaward of the mouth are similar.

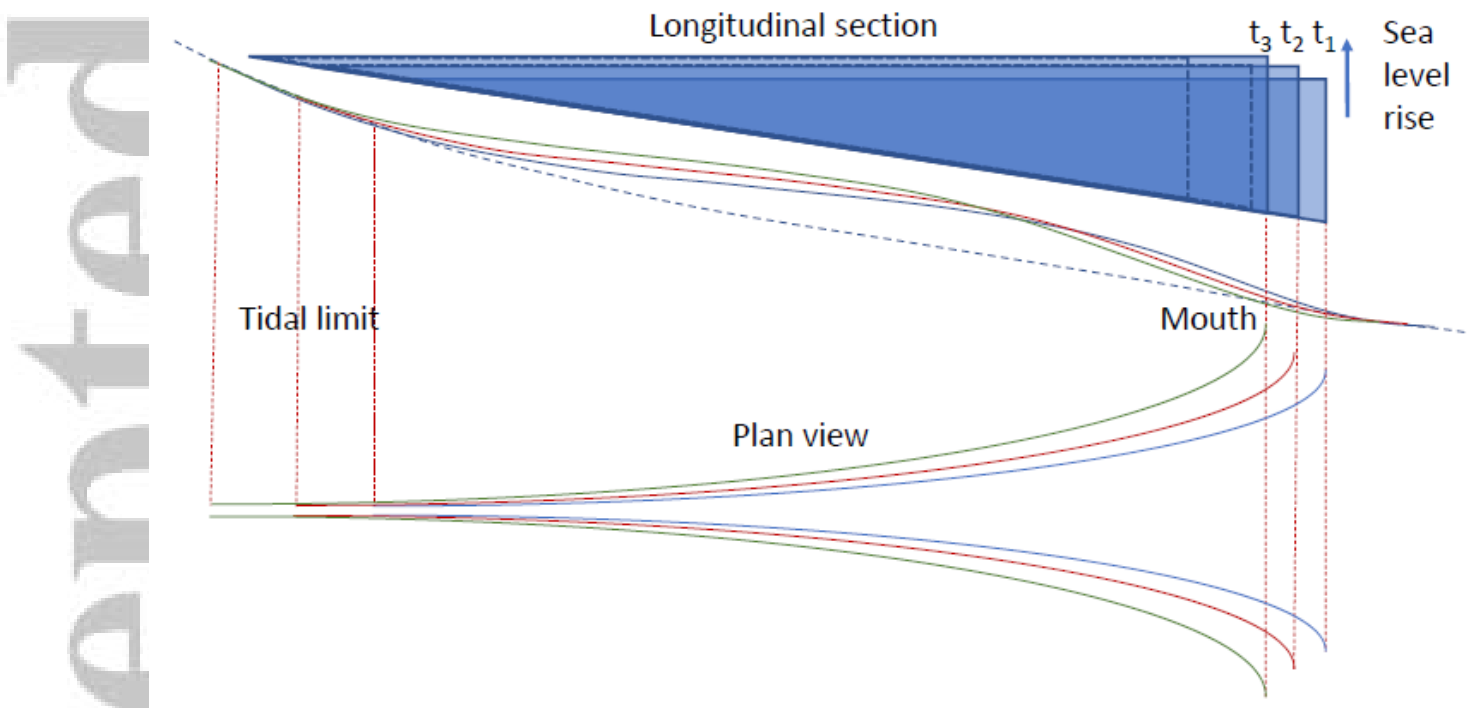

12(b) Rate of transgression of the estuary mouth is substantially less than that of the estuary. To maintain a similar equilibrium form, the original system moves landwards (as indicated by the dashed blue lines in the upper section) and the estuary lengthens, and widens and deepens at the mouth. The overall change in length depends on the river valley slope at the tidal limit. The deepening at the mouth implies a flattening of the relict estuary transgression slope.

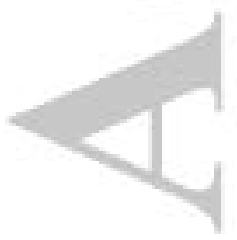

This article is protected by copyright. All rights reserved. 


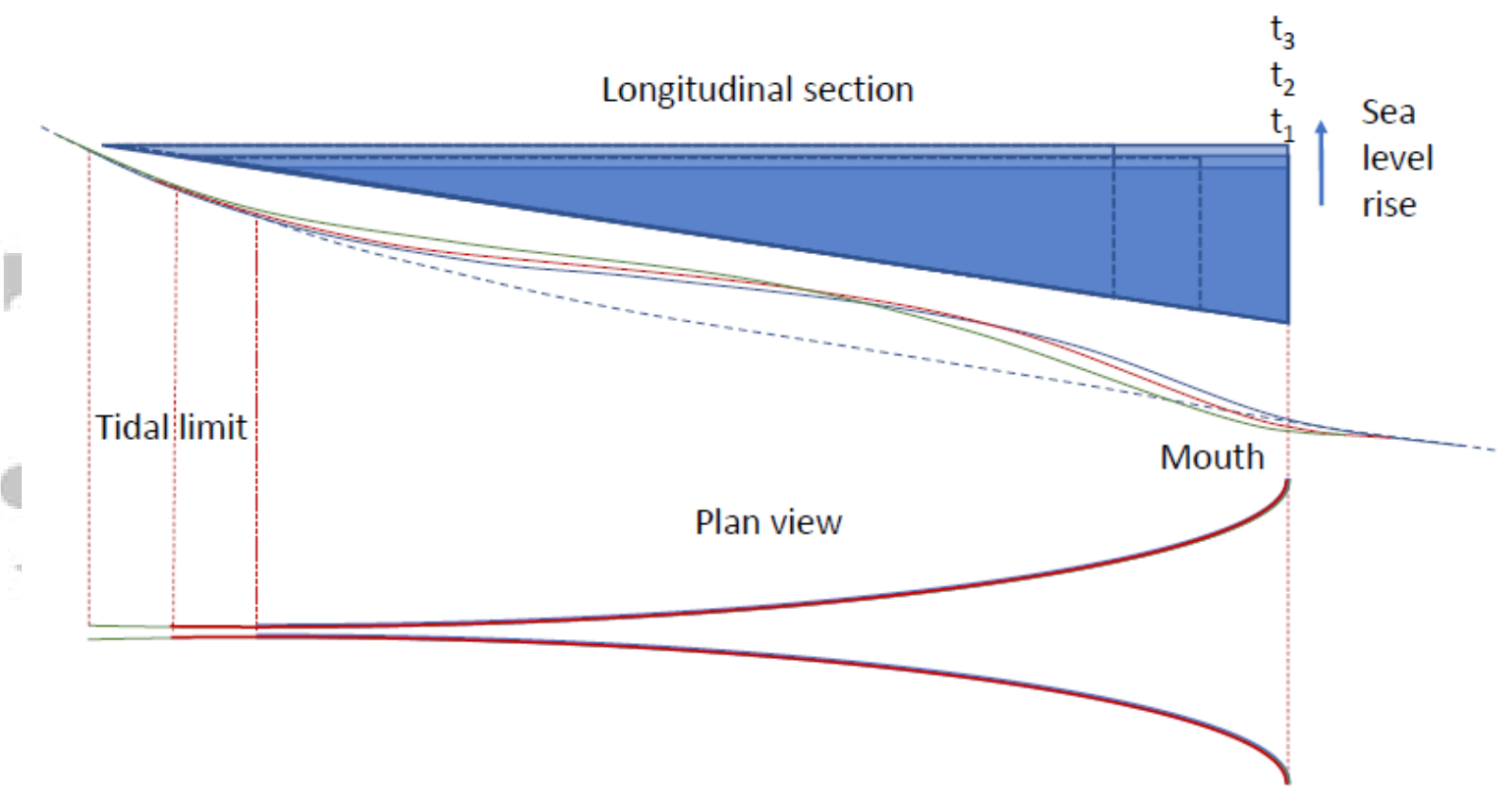

12(c) If the estuary is constrained so that the high-water plan form remains constant, the estuary continues to extend landwards, with deepening at the mouth and an increase in bed level further upstream to maintain depths relative to the water surface. The deepening at the mouth implies a flattening of the relict estuary transgression slope

Figure 12- Conceptual models of transgression with differing rates of mouth and width constraint. Each plot has 3 parts. The upper longitudinal section, in blue, shows the transgression of a simple prismatic section, whereas the longitudinal section coloured lines below show how the thalweg for the idealised form examined changes over three time intervals in response to a linear rate of sea level rise. The plan view shows how the widths adjust depending on the nature of the transgression.

This article is protected by copyright. All rights reserved. 
Table 1 - Valley and estuary properties

\begin{tabular}{|l|c|c|c|}
\hline \multicolumn{1}{|c|}{ Property } & $\begin{array}{c}\text { Short, steep } \\
\text { valley }\end{array}$ & $\begin{array}{c}\text { Long, steep } \\
\text { valley }\end{array}$ & $\begin{array}{c}\text { Long, flat } \\
\text { valley }\end{array}$ \\
\hline Valley length $(\mathrm{km})$ & 50 & 300 & 300 \\
\hline Elevation at valley head $\left(\mathrm{mAD}^{*}\right)$ & 500 & 300 & 100 \\
\hline Along valley aspect ratio $(\mathrm{L} / \mathrm{H})$ & 100 & 1000 & 3000 \\
\hline Catchment area $\left(\mathrm{km}^{2}\right)$ & 600 & 24000 & 12000 \\
\hline River discharge $\left(\mathrm{m}^{3} / \mathrm{s}\right)$ & 50 & 200 & 100 \\
\hline Valley width at mouth $(\mathrm{km})$ & 4 & 20 & 20 \\
\hline Holocene basal level at mouth $\left(\mathrm{mAD}^{*}\right)$ & -35 & -15 & -15 \\
\hline Distance to tidal limit $(\mathrm{km})$ & 12 & 140 & 160 \\
\hline Tidal amplitude $(\mathrm{m})$ & $2^{+}$ & 3 & 3 \\
\hline Width of mouth at high water $(\mathrm{km})$ & 1.2 & 10 & 10 \\
\hline
\end{tabular}

Notes: * metres Above Datum. ${ }^{+}$although a smaller amplitude was used for this case, increasing this to $3 \mathrm{~m}$ has only a small influence because the valley is short and steep.

\section{Table 2 - Summary of cases examined}

\begin{tabular}{|l|c|c|c|}
\hline & Short, steep valley & Long, steep valley & Long, flat valley \\
\hline Full flood plain & $2 \times \mathrm{SLR}$ & $2 \times \mathrm{SLR}$ & $2 \times$ SLR \\
\hline Half flood plain & $2 \times \mathrm{SLR}$ & $2 \times \mathrm{SLR}$ & $2 \times$ SLR \\
\hline Mouth flood plain & $2 \times \mathrm{SLR}$ & $2 \times \mathrm{SLR}$ & $2 \times \mathrm{SLR}$ \\
\hline No flood plain & $2 \times \mathrm{SLR}$ & $2 \times \mathrm{SLR}$ & $2 \times \mathrm{SLR}$ \\
\hline Tidal amplitude & $+/-10 \%$ & $+/-10 \%$ & $+/-10 \%$ \\
\hline Sediment supply & $0.5 \mathrm{C}_{\mathrm{E}}$ and $2 \mathrm{C}_{\mathrm{E}}$ & $0.5 \mathrm{C}_{\mathrm{E}}$ and $2 \mathrm{C}_{\mathrm{E}}$ & $0.5 \mathrm{C}_{\mathrm{E}}$ and $2 \mathrm{c}_{\mathrm{E}}$ \\
\hline Constraints & - & Illustration & - \\
\hline
\end{tabular}

Note: the two SLR cases and the changes to tidal amplitude are progressive changes over the simulation period, whereas the initial condition is adjusted to examine the sensitivity to sediment supply. 


\section{A morphological investigation of marine transgression in estuaries}

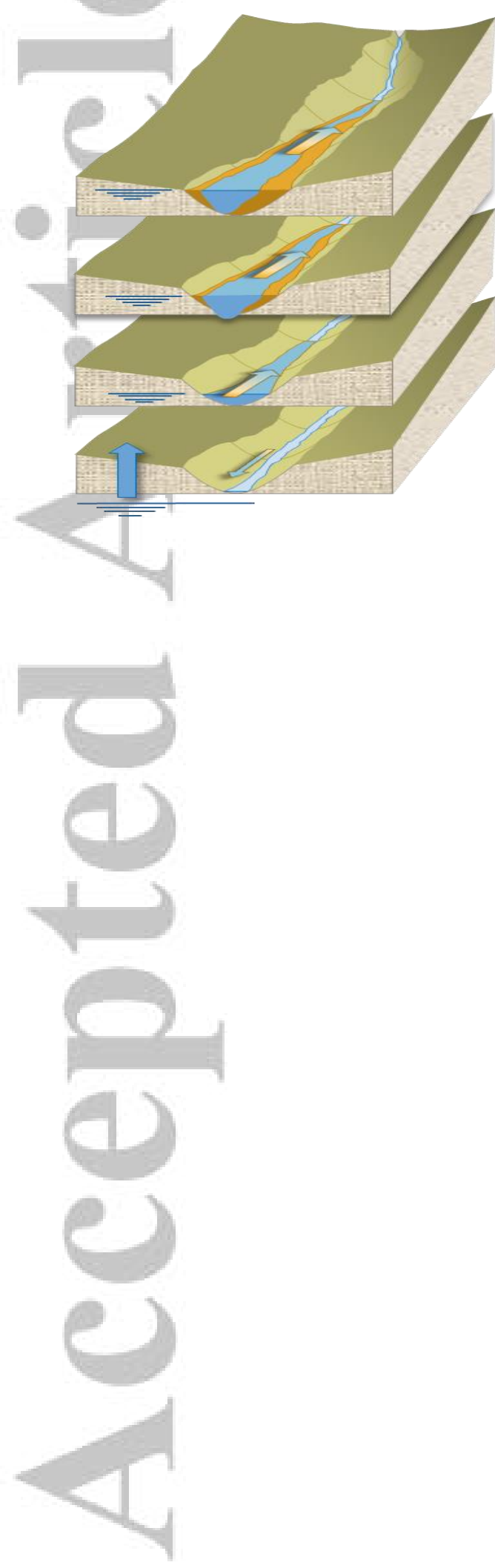

An estuary can maintain its form relative to rising sea level by translating landwards. The transgression distance is dependent on the sediment demand to fill the accommodation space in the surrounding valley and is sensitive to the rate of sea level rise and sediment availability. Exclusion of flood plains, by flood defences, may be creating a "coiled spring" effect, which when released, as defences fail or are removed, will create an increase in accommodation space and the potential for estuary transgression.

lan Townend, Zeng Zhou, Leicheng Guo, and Giovanni Coco

This article is protected by copyright. All rights reserved. 